\title{
DLX5/6 GABAergic Expression Affects Social Vocalization: Implications for Human Evolution
}

\author{
Giovanni Levi (D), ${ }^{1}$ Camille de Lombares, ${ }^{1}$ Cristina Giuliani $\mathbb{D}^{2},{ }^{2}$ Vincenzo lannuzzi, ${ }^{3}$ Rym Aouci, \\ Paolo Garagnani (D), ${ }^{4,5}$ Claudio Franceschi (D), ${ }^{4,6}$ Dominique Grimaud-Hervé (D), ${ }^{7}$ and \\ Nicolas Narboux-Nême (D),1
}

\begin{abstract}
${ }^{1}$ Physiologie Moléculaire et Adaptation, CNRS UMR7221, Département AVIV, Muséum National d'Histoire Naturelle, Paris, France ${ }^{2}$ Laboratory of Molecular Anthropology \& Centre for Genome Biology, Department of Biological, Geological and Environmental Sciences, University of Bologna, Italy

${ }^{3}$ Alma Mater Research Institute on Global Challenges and Climate Change, University of Bologna, Italy

${ }^{4}$ Department of Experimental, Diagnostic and Specialty Medicine (DIMES), University of Bologna, Bologna, Italy

${ }^{5}$ Clinical Chemistry, Department of Laboratory Medicine, Karolinska Institutet at Huddinge University Hospital, Stockholm, Sweden

${ }^{6}$ Institute of Information Technologies, Mathematics and Mechanics, Lobachevsky University, Nizhniy Novgorod, Russia

${ }^{7}$ Histoire Naturelle de l'Homme Préhistorique, CNRS UMR 7194, Département H\&E, Muséum National d'Histoire Naturelle, Paris, France
\end{abstract}

*Corresponding author: E-mail: nnarboux-neme@mnhn.fr.

Associate editor: Evelyne Heyer

\section{Abstract}

DLX5 and DLX6 are two closely related transcription factors involved in brain development and in GABAergic differentiation. The DLX5/6 locus is regulated by FoxP2, a gene involved in language evolution and has been associated with neurodevelopmental disorders and mental retardation. Targeted inactivation of Dlx5/6 in mouse GABAergic neurons (Dlx5/6 ${ }^{\text {VgatCre }}$ mice) results in behavioral and metabolic phenotypes notably increasing lifespan by $33 \%$. Here, we show that $D l \times 5 / 6^{V \text { gatCre }}$ mice present a hyper-vocalization and hyper-socialization phenotype. While only $7 \%$ of control mice emitted more than 700 vocalizations $/ 10 \mathrm{~min}, 30 \%$ and $56 \%$ of heterozygous or homozygous $D / \times 5 / 6^{v g a t c r e}$ mice emitted more than 700 and up to 1,400 calls/10 min with a higher proportion of complex and modulated calls. Hyper-vocalizing animals were more sociable: the time spent in dynamic interactions with an unknown visitor was more than doubled compared to low-vocalizing individuals. The characters affected by Dlx5/6 in the mouse (sociability, vocalization, skull, and brain shape...) overlap those affected in the "domestication syndrome". We therefore explored the possibility that DLX5/6 played a role in human evolution and "self-domestication" comparing DLX5/6 genomic regions from Neanderthal and modern humans. We identified an introgressed Neanderthal haplotype (DLX5/6-N-Haplotype) present in $12.6 \%$ of European individuals that covers DLX5/6 coding and regulatory sequences. The DLX5/6- $\mathrm{N}$-Haplotype includes the binding site for GTF2I, a gene associated with Williams-Beuren syndrome, a hyper-sociability and hyper-vocalization neurodevelopmental disorder. The DLX5/6-N-Haplotype is significantly underrepresented in semi-supercentenarians ( $>105$ years of age), a well-established human model of healthy aging and longevity, suggesting their involvement in the coevolution of longevity, sociability, and speech.

Key words: DLX5/6 genes, ultrasonic vocalization, aging, social behavior, human evolution, self-domestication.

\section{Introduction}

Within groups of animals, vocal calls play an essential role in directing social behavior, in transmitting information about food availability and predators and for reproductive and maternal activities. In humans, vocal communication and speech constitute major socialization determinants; their dysfunction represents a core trait of neurodevelopmental conditions such as Autism Spectrum Disorders (ASDs). Several mouse models characterized by genetic lesions associated with human neurodevelopmental disorders have been used to study the genetic and neurological mechanisms supporting the interplay between vocalization and socialization
(Caruso, et al. 2020). Mice social behaviors are accompanied by the production of ultrasonic vocalizations (USVs) (Sales 1972) which, in the case of most laboratory strains, present a frequency included between 35 and $110 \mathrm{kHz}$ (Holy and Guo 2005). Mice USVs profiles vary with the type of social activity performed (e.g., courtship, aggression, and fear), with the animal's developmental stage, with their genetic background and can be altered by induced genetic modifications. Although the link between USVs profiles and social activity is still incompletely analyzed, recent studies have implemented artificial intelligence algorithms to associate USVs of individual mice to specific social actions (Ey, et al. 2020;

(C) The Author(s) 2021. Published by Oxford University Press on behalf of the Society for Molecular Biology and Evolution. This is an Open Access article distributed under the terms of the Creative Commons Attribution Non-Commercial License (http://creativecommons.org/licenses/by-nc/4.0/), which permits non-commercial re-use, distribution, and reproduction in any medium, provided the original work is properly cited. For commercial re-use, please contact journals.permissions@oup.com 
Sangiamo, et al. 2020), unveiling a functional correlation between specific USVs and social behaviors. The generation of voluntary structured vocalizations requires the coordination of different levels of cognitive and motor activities and involves a complex and diffuse neural network ranging from the prefrontal and motor cortical areas for voluntary initiation of vocalization to several forebrain and brainstem regions for the control of laryngeal movements and respiration (Jurgens 2002; Simonyan 2014). The inputs/outputs to this network are integrated in the midbrain periaqueductal gray (PAG), the central neural region controlling vocalization in most mammalians (Jurgens 2009; Tschida, et al. 2019).

The study of developmental disorders affecting vocal communication such as stuttering, verbal dyspraxia, and some types of ASDs has led to the identification of genes involved in the control of speech and/or socio/cognitive faculties (Konopka and Roberts 2016). The most intensively studied of them, the transcription factor FOXP2, is associated with inherited dyspraxia and poor control of the facial musculature. Other "language-associated" genes include for example SHANK $1 / 2 / 3$, FOXP1, GNPTAB, GNPTG, CNTNAP2, and NAGPA; for most of these genes mouse models have been generated resulting almost invariably in alteration of USV and social behavior (Wohr 2014; Caruso, et al. 2020). These animal models suggest that a certain level of conservation exists between the mechanisms controlling vocalization. Homozygous disruption of Foxp2 in the mouse cerebral cortex results in abnormal social approach and altered USVs (Medvedeva, et al. 2019). One of the targets of Foxp2 is the D/x5/6 locus: the mouse line Foxp2-S321X, which does not produce Foxp2 protein, displays a more than 200-fold increased expression of Dlx6as 1 (also known as Evf1/2 or Shhrs) (Vernes, et al. 2006) a long noncoding RNA generated from the D/x5/6 locus known to play a central role in the control of $D / x$ gene expression (Faedo, et al. 2004; Feng, et al. 2006).

$D L X 5 / 6$ are pleiotropic genes that control multiple aspects of embryonic development (Merlo, et al. 2000), including limb, craniofacial, and laryngeal morphogenesis (Beverdam, et al. 2002; Depew, et al. 2002; Robledo, et al. 2002; Conte, et al. 2016) and GABAergic neuronal differentiation and function (Perera, et al. 2004; Wang, et al. 2010; Cho, et al. 2015; de Lombares, et al. 2019).

In humans, mutations in a $1.5 \mathrm{Mb}$ genomic region including DLX5/6 are associated with Split Hand/Foot Malformation type 1 (SHFM1) (Scherer, et al. 1994; Crackower, et al. 1996), a form of ectrodactyly which can be accompanied by sensorineural deafness, craniofacial malformations with or without intellectual disability (Birnbaum, et al. 2012; Rasmussen, et al. 2016). Recently, a large-scale transcriptomic study on postmortem brains has suggested that the DLX5/6 locus participates to genetic modules involved in ASDs and schizophrenia (Gandal, et al. 2018).

During aging, the methylation state of many genes increases or diminishes linearly giving rise to the "methylation clock" which permits to estimate the biological age of organisms, including humans (Guarasci, et al. 2019). The methylation status of the $D L X 5 / 6$ gene locus increases linearly with age in several mouse and human tissues including the brain
(Bell, et al. 2012), suggesting that $D L X 5 / 6$ expression could be associated with phenotypic changes in aging and lifespan.

The general inactivation of $D / \times 5 / 6$ in the mouse results in perinatal death with a SHFM1 phenotype associated with severe craniofacial defects (Beverdam, et al. 2002; Depew, et al. 2002) while their targeted inactivation only in cephalic neural crest cells (CNCCs) results in more limited craniofacial defects (Shimizu, et al. 2018). In the brain, D/x5/6 are selectively expressed by GABAergic neurons. Recently, by crossing Dlx5/fox flice with Vgat $^{\text {cre }}$ transgenic animals in which the "Cre-recombinase" gene is expressed selectively by GABAergic neurons, we have generated mice in which the DIx5/6 DNAbinding capacity is reduced (D/x5/6 VgatCre/+$)$ or suppressed (Dlx5/6 VgatCre) only in GABAergic neurons (de Lombares, et al. 2019). D/x5/6 $6^{\text {VgatCre/+}}$ and D/x5/6 ${ }^{\text {VatCre }}$ mice present reduced anxiety, compulsivity, and adiposity, associated with a $33 \%$ life expectancy extension (de Lombares, et al. 2019). In this study, we show that D/x5/6 $6^{\text {VatCre/+ }}$ and D/x5/ $6^{\text {Vgatcre }}$ mice also present different social behaviors and vocalization patterns when compared to their littermates.

It has long been noted that morphological differences between modern and archaic Homo is similar to those of domesticated species (Boas 1938). The set of characters affected by Dlx5/6 in the mouse is reminiscent of those distinguishing domesticated species from their wild counterparts (Wilkins, et al. 2014), the so-called "domestication syndrome" characterized by increased socialization and by morphological changes in brain-case shape and size, retraction of the face, and decreased tooth size (Sánchez-Villagra and van Schaik 2019). A similar set of morphological and behavioral changes also occurred in wild house mice that adapted to life in close contact to humans (Geiger, et al. 2018). The "self-domestication hypothesis" suggests that human evolution (Zanella, et al. 2019) can be better understood in the light of a domestication process leading to increased socialization and communication accompanied by progressive changes in morphological characters such as craniofacial features (for a review, see Šimić, et al. 2020).

Modern humans, the sole survivor of the group of hominins, differ from other Hominidae by many anatomical and physiological characters and, most remarkably, for their cognitive and linguistic capacities which reflect the singularity of our brain. Comparison of modern and archaic Homo genomes has played a pivotal role in the quest of Homo sapiens evolutionary history and in defining what makes us modern humans (see e.g., Prufer, et al. 2014; Racimo, et al. 2014; Racimo 2016; Peyregne, et al. 2017; Hajdinjak, et al. 2018).

Comparison of Neanderthal, Denisovan, and modern human genomes has shown that interbreeding occurred between these different human groups until 45,00065,000 years ago (Meyer, et al. 2012; Sankararaman, et al. 2014; Dannemann, et al. 2016; Vernot, et al. 2016). Negative selection against introgression is expected to have had the strongest impact on genome-wide Neanderthal ancestry during the few early generations after admixture, while some introgressed regions were conserved, and were even under positive selection. Moreover, drift and demographic events 
(such as admixture) can determine shifts in ancestry proportions (Harris and Nielsen 2016; Petr, et al. 2019). There is increasing interest to decode the biological, phenotypic, and medical consequences of Neanderthal legacy in the modern human genome (Simonti, et al. 2016; Dolgova and Lao 2018; Rotival and Quintana-Murci 2020).

To understand the coevolution of human traits, a particular attention has been given to pleiotropic genes, which can simultaneously control the development of numerous characters. For example, in prospective studies trying to identify genes capable of affecting simultaneously craniofacial shape, osteogenesis, and language abilities Boeckx and BenitezBurraco have proposed a network of physically or functionally interconnected genes including the RUNX, FOXP, and DLX families and their regulators (Boeckx and Benitez-Burraco 2014b, 2015).

Here, we show that the inactivation of D/x5/6 in mouse GABAergic neurons results in a hyper-vocalization phenotype and in a sharp increase of dynamic social interactions. Furthermore, we identify an introgressed Neanderthal haplotype (DLX5/6-N-Haplotype) representing 6.3\% of European alleles, which covers $D L X 6$ and $D L X 5$ coding and regulatory sequences including SNPs associated with either hyper(Williams-Beuren syndrome) or hypo- (ASDs) sociability and vocalization syndromes (Poitras, et al. 2010).

\section{Results}

\section{Dlx5/6 Expression in GABAergic Neurons Affects Mouse Social Ultrasonic Vocalizations}

To analyze the social ultrasonic vocalization phenotypes (UVs) resulting from the simultaneous deletion of $D / \times 5 / 6$ homeodomains in adult GABAergic neurons, we applied the resident/ intruder experimental paradigm to groups of control, $D / \times 5 /$ $6^{\text {VgatCre/+ }}$ (heterozygous deletion) and D/x5/6 ${ }^{\text {VgatCre }}$ (homozygous deletion) adult female mice (Moles, et al. 2007).

In this experimental setting, the animals to be tested (resident) are isolated 3 days before being exposed to an unfamiliar group-housed control adult mouse (intruder). Although UVs are simultaneously recorded for the pair of mice (resident and intruder), previous studies have shown that the contribution of the new comer is minor in comparison to that of the occupant (Hammerschmidt, et al. 2012).

The number and types of vocalizations emitted during a $10 \mathrm{~min}$ test period (v/10 min) by $10 \mathrm{D} / \times 5 / 6^{\mathrm{VgatCre} /+}, 9 \mathrm{D} / \times 5 /$ $6^{\text {VgatCre }}$, and 15 control females confronted to a control female intruder were individually recorded. Most (14/15; 93\%) control mice emitted less than $700 \mathrm{v} / 10 \mathrm{~min}$ and only one emitted $849 \mathrm{v} / 10 \mathrm{~min}$. In contrast, $30 \%(3 / 10)$ of the D/x5/6 $6^{\text {VatCre/+ }}$ and $56 \%$ (5/9) of the D/x5/6 $6^{\text {vatcre }}$ mice presented a unique vocalization profile emitting more than $700 \mathrm{v} / 10 \mathrm{~min}$, with two heterozygous and four homozygous emitting more than $1,000 \mathrm{v} / 10 \mathrm{~min}$ and up to $1,400 \mathrm{v} /$ $10 \mathrm{~min}$ (fig. $1 A$ and $B$ ).

This observation demonstrates the presence of an incompletely penetrant vocalization phenotype associated with the
A Number of calls/10 min in different genotypes

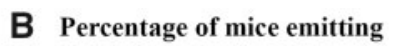
more or less than 700 calls/10 min
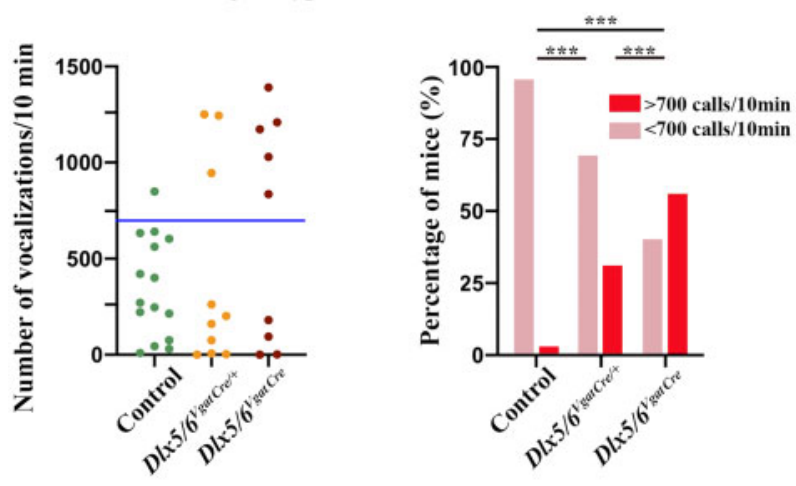

FIG. 1. Number of calls/10 min emitted by D/x5/6 VgatCre/+ and D/x5/ $6^{\text {VgatCre }}$ mice. Number of calls emitted by of D/x5/6 ${ }^{\text {VgatCre/+ }}(n=10)$, Dlx5/6 ${ }^{\text {VgatCre }}(n=9)$, and control $(n=15) 6$ months old female mice confronted to a genetically normal female mouse intruder for $10 \mathrm{~min}$. The number and types of vocalization were quantified. (A) $93 \%$ of control mice emitted less than 700 vocalizations during the $10 \mathrm{~min}$ tests, only one outlier emitted 849 calls. In contrast, $30 \%$ of $\mathrm{Vgat}^{\Delta D / x 5 \text { - }}$ ${ }^{6 /+}(3 / 10)$ and $56 \%$ of $\operatorname{Vgat}^{\Delta D / \times 5-6}(5 / 9)$ mice emitted between 850 and 1400 calls/10 min. (B) Percentage of mice emitting less (pink) or more (red) than 700 calls/10 $\mathrm{min}$. The difference between each genotype is highly significant $\left({ }^{* * *} P<0.001\right.$, Chi-square test).

reduction of the level of expression of D/x5/6 in GABAergic neurons, characterized by an allele-dosage-dependent increase in the number of calls per minute.

Some illustrative examples of vocalization profiles recorded from normal and mutant resident mice are presented in figure 2. Control animals (fig. $2 A-D$ ) and low-vocalizing mutants (fig. $2 \mathrm{G}$ and $H$ ) emitted bursts of vocal signals separated by silent intervals or did not emit any call for long periods of time (fig. $2 H$ ). In contrast, the high-vocalizing D/ $\times 5 / 6^{\text {VgatCre }}$ mice emitted uninterrupted series of calls extending for many seconds without any detectable interruption or pause (fig. $2 E$ and $F$ ), this pattern of vocalization being never observed in control animals.

The total time spent vocalizing by mice emitting a high number of vocalizations was about 4 times longer than that of low-vocalizing littermates (fig. $3 A$ ). We categorized the types of vocalization emitted in five major groups short, simple, complex, frequency jumps, and unstructured as previously described (Ey, et al. 2013). The analysis of the specific types of calls emitted by each animal showed that highvocalizing animals presented a significant increase in the number of complex vocalizations ("modulated + complex" according to Ey, et al. (2013)) which are the longest vocalization types emitted by mice and can last up to $0.15 \mathrm{~ms}$ (fig. 3B). Complex vocalizations have been recently associated with more social behaviors (Ey, et al. 2020). Therefore, in this experimental paradigm, designed to detect social vocalization, we observed a new partially penetrant phenotype characterized by an increase in the number calls, and differences in vocal repertoire and "prosody" (Lahvis, et al. 2011). 

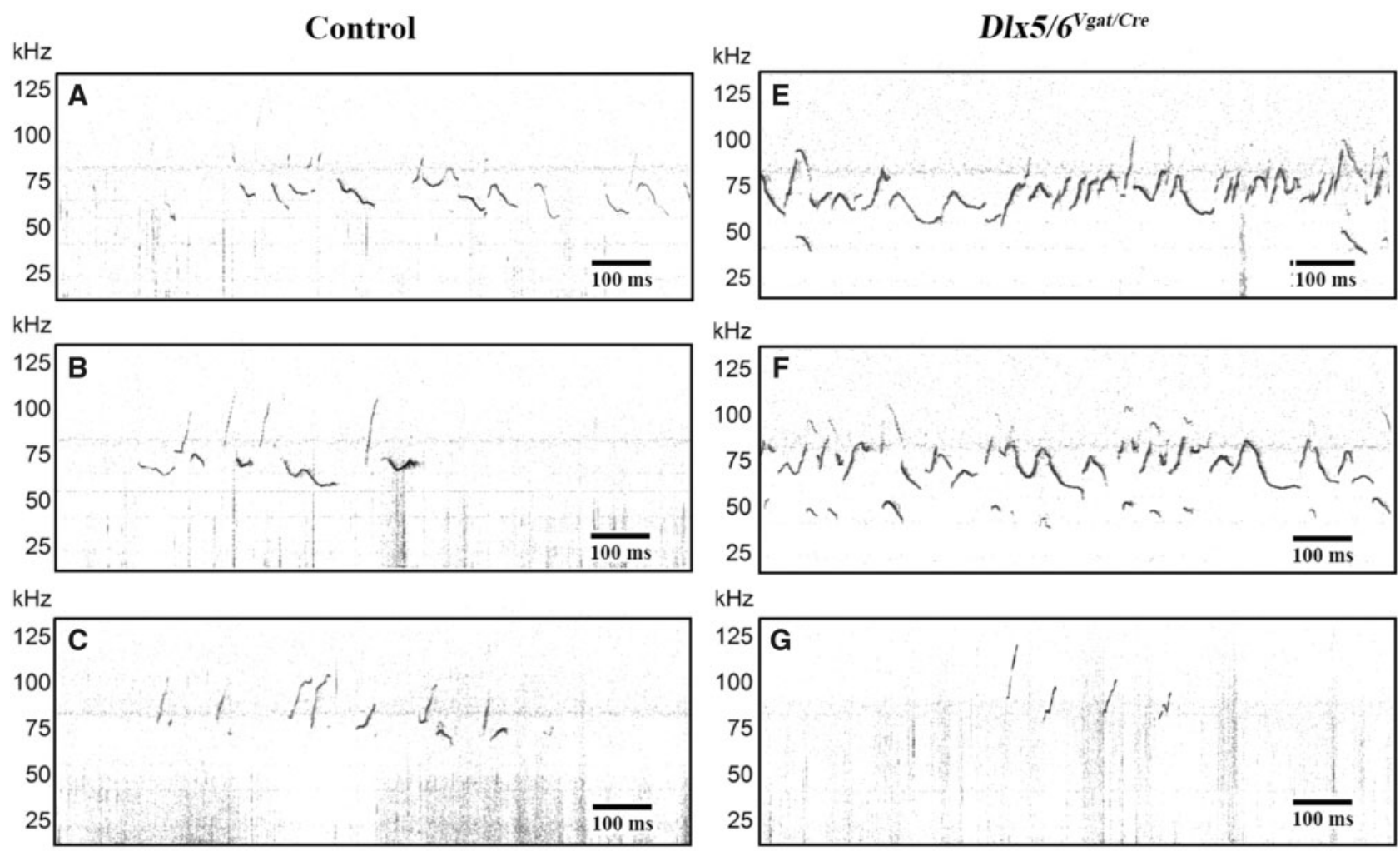

$\mathrm{kHz}$
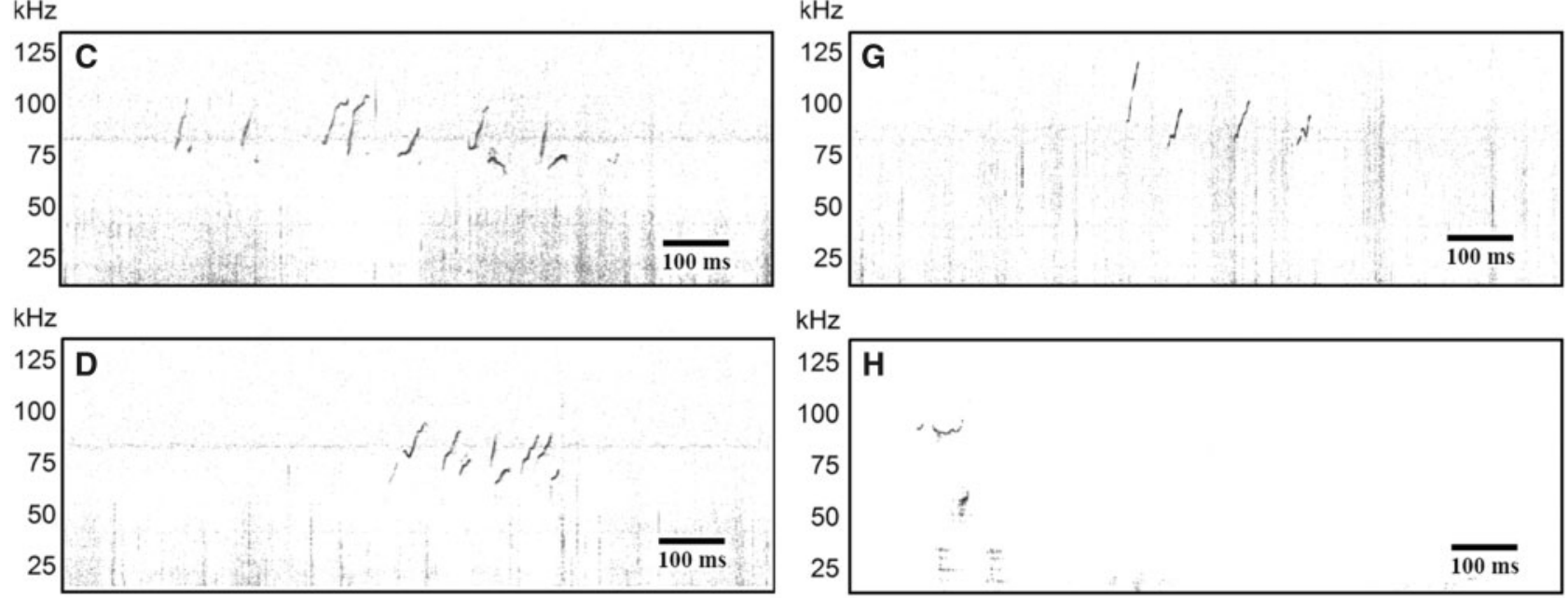

Fig. 2. Spectrograms of control and $D / \times 5 / 6^{\text {VgatCre }}$ mice. Representative spectrograms from four controls $(A-D)$ and four $D / \times 5 / 6^{\text {VgatCre }}(E-H)$ mice. In each group of animals, some individuals (e.g., $D, H$ ) emitted very few vocalizations while others emitted sequences of calls separated by silent intervals $(A-C, G)$. Hyper-vocalizing D/x5/6 ${ }^{\text {VgatCre }}$ mice emitted long, uninterrupted, sequences of calls $(E, F)$ which were never observed in controls or low-vocalizing animals.
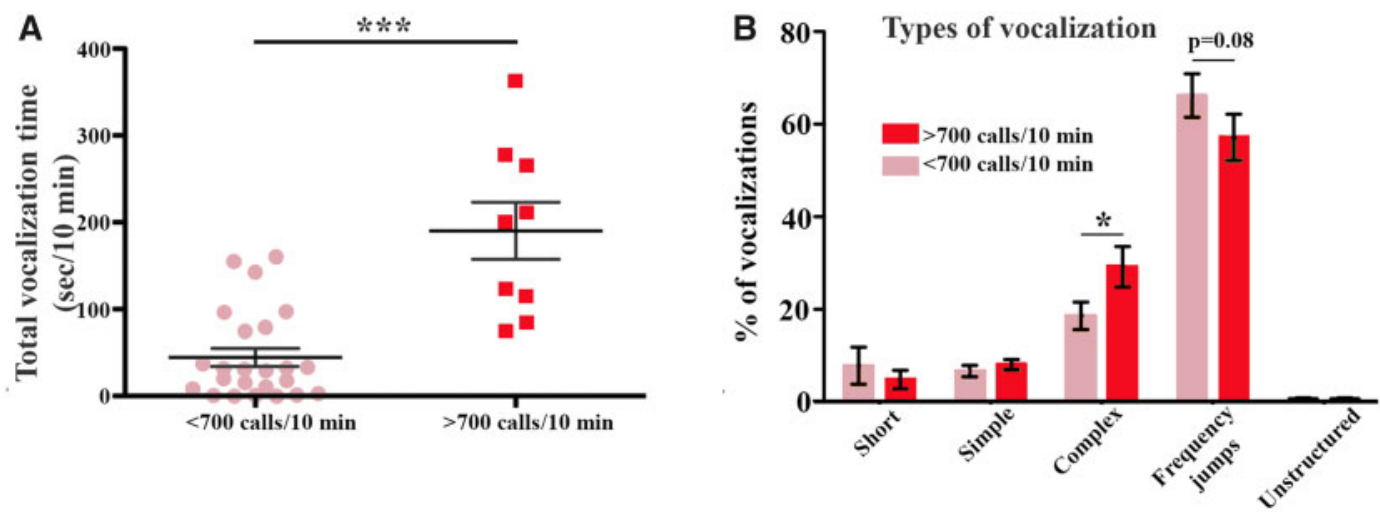

Fig. 3. Total vocalization time and call types emitted by hyper-vocalizing and low-vocalizing mice. $(A)$ Total time spent vocalizing by mice emitting less or more than 700 calls/10 min. (B) Percentage of call types produced by mice emitting less or more than 700 calls/10 min. Five types of emissions have been considered as in Ey, et al. (2013): Short, Simple (Flat + Upward + Downward), Complex (Modulated + Complex), Unstructured, and Frequency jumps. Hyper-vocalizing animals vocalize, in average, four times more than low vocalizing animals and emit significantly more complex and modulated calls. ( ${ }^{* * *} P<0.001$; ${ }^{*} P<0.05$, Mann-Whitney $U$ test). 

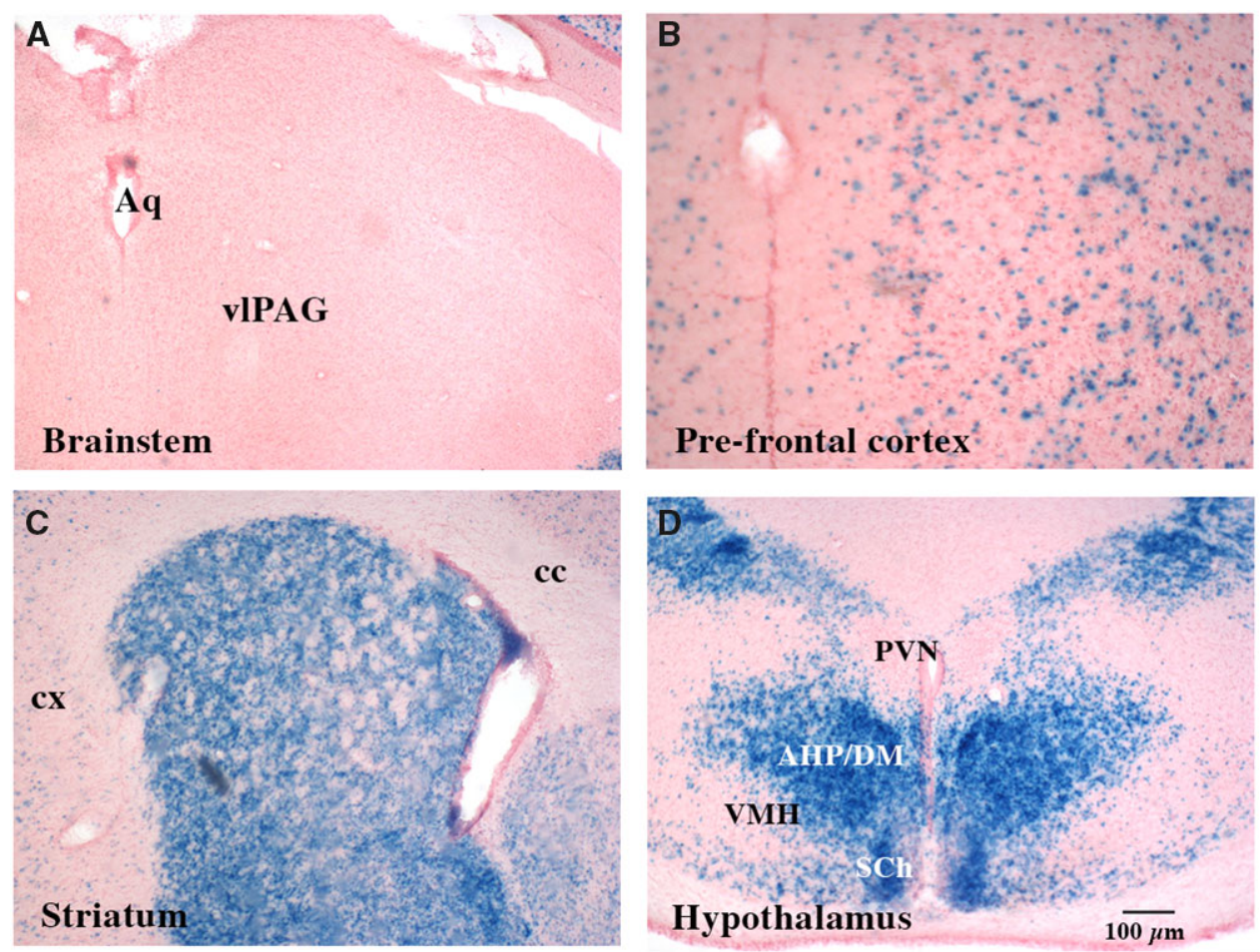

FiG. 4. Expression of Dlx5 in different adult brain regions involved in vocalization. $X$-gal staining on serial sections of Dlx $5^{\text {lacz/+ }}$ brains. $\beta$ Galactosidase activity was not detected in the brainstem $(A)$, in the cerebellum and in the midbrain including the ventro-lateral periacqueductal gray (vIPAG) a region which integrates sensory and cognitive inputs and controls vocalization motor centers. D/ 55 was expressed in the prefrontal cortex $(B)$ and in other cortical regions $(c x)$, in the striatum $(C)$ and in hypothalamic nuclei $(D)$. AHP, anterior hypothalamic area; $c c$, corpus callosum; cx, cortex; DM, Dorsomedial hypothalamus; PVN, para-ventricular nucleus; SCh, suprachiasmatic nucleus; VMH, ventro medial hypothalamus.

\section{D/x5/6 Expression in Brain Regions Which Control Vocalization}

Vocal communication depends on a complex neural network that includes regions of the forebrain, of the basal ganglia, and of the brainstem (Jurgens 2002). These multiple inputs are integrated by the periaqueductal gray (PAG), a midbrain territory that is at the interface between the telencephalon and phonation/respiration motor centers. As all these brain territories include GABAergic neurons, we determined in which of them D/x5 is expressed. To this end, we analyzed the distribution of $B$-galactosidase staining in Dlx $5^{\text {lacz }}$ adult mouse brains (fig. 4) (Acampora, et al. 1999). We found that Dlx5 is not expressed in the PAG or other midbrain regions (fig. 4A) nor in posterior motor areas. On the contrary, D/x5 is strongly expressed in the cerebral cortex (fig. $4 \mathrm{~B}$ ), in the hypothalamus (fig. 4C), and in the striatum (fig. 4D). These observations suggest that Dlx5/6 affect central cognitive and emotional inputs to vocal communication but do not affect the "mechanics" of phonation.

\section{Social Behavior of Hyper-Vocalizing Mice}

The social behavior of the mice on which we had quantified UVs was analyzed with the resident/intruder experimental setting described above. Behavior and social interactions were filmed and analyzed as previously described (de Chaumont, et al. 2019). Social behavior between individuals of the same genotype was very variable, resulting in no significant difference in sociability between control, D/x5/ $6^{\text {VgatCre/+ }}$ and D/x5/6 $6^{\text {VgatCre }}$ mice (de Lombares, et al. 2019). However, when we confronted the groups of hyper-vocalizing ( $>700$ calls/10 min) and low-vocalizing ( $<700$ calls/10 min) animals, we found a highly significant association between hyper-vocalization and hyper-sociability. Hyper-vocalizing animals spent more than twice the time following or approaching the intruder than the low-vocalizing individuals (fig. $5 A$ and $B$ ).

Therefore, the same animals in which the mutation of D/x5/6 in GABAergic neurons induced hyper-vocalization presented also a hyper-sociability phenotype.

\section{Introgression of a Neandertal-like Haplotype in the DLX5/6 Locus}

Patients carrying mutations in the DLX5/6 locus or mouse models in which these genes are deregulated present abnormalities in at least five sets of characters which differentiate $H$. sapiens from Homo Neanderthalensis: 1) brain size and shape, 2) limb morphology, 3) craniofacial shape, 4) middle ear morphology, and 5) bone density.

Comparing the DLX5/6 locus of modern humans (fig. 6A) to those of Neanderthal (Altaï, Vindija), Denisovan, and other Hominidae, we identified 298 SNPs with rare alleles that are shared between modern humans and Neanderthals and are absent from African populations in an interval of $400 \mathrm{~kb}$ centered on D/ $\times 5$ coding sequences. Among them we identified, 


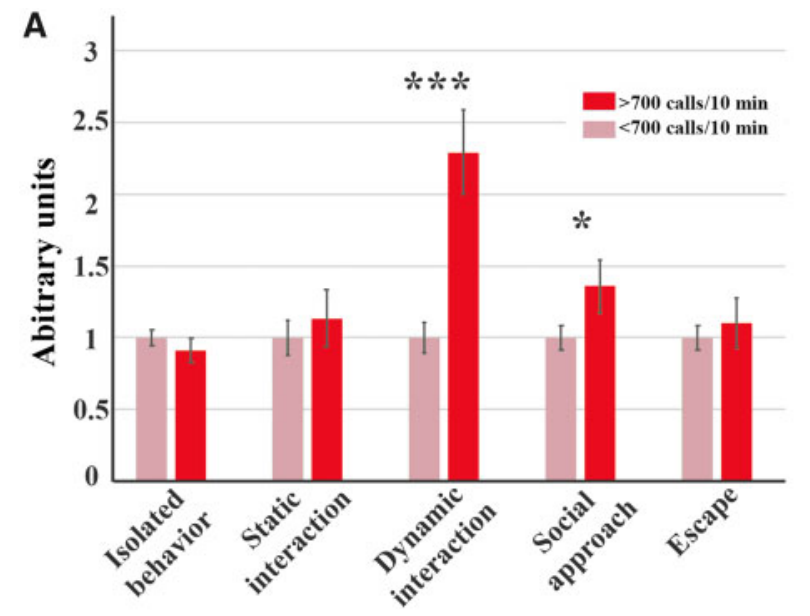

B
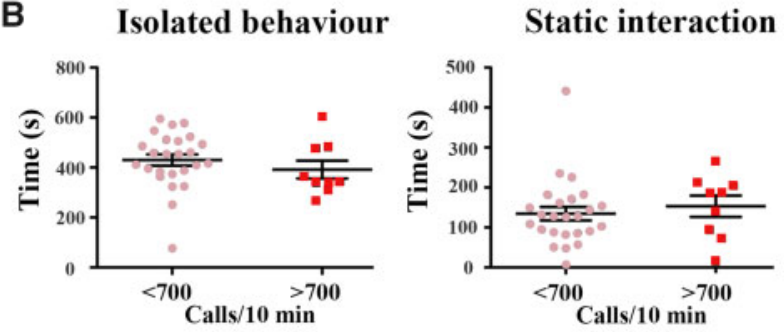

Dynamic interaction

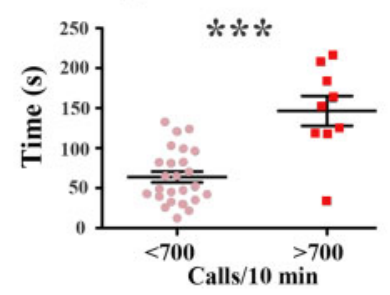

Social approach

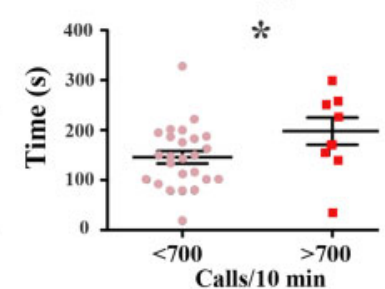

FIG. 5. Social behavior of hyper-vocalizing and low-vocalizing mice. The social interaction behavior of Dlx5/6 $6^{\text {VatCre/+ }}(n=10)$, Dlx5/ $6^{\text {VgatCre }}(n=9)$, and control $(n=15)$ mice placed in the same cage with a control visitor was monitored using a protocol (de Chaumont, et al. 2019; de Lombares, et al. 2019), which associates computer vision and artificial intelligence to identify and categorize individual social interactions. The types of behavior recorded were classified as follows: 1) isolated behavior (moving alone, rearing alone, stopped alone, jump alone, huddling alone), 2) static interactions (rearing in contact, oral-oral contact, oro-genital contact, side-by-side in same or opposite orientation, 3 ) dynamic interactions (moving in contact, train of 2 mice, following the same path), 4) Social approach (making contact, approaching in rearing, approaching), 5) social escape (breaking contact, escaping), a detailed description of each behavior is found in (de Chaumont, et al. 2019). The time spent by each mouse (s) adopting a specific behavior was measured over a $10 \mathrm{~min}$ recording. (A) Normalized results: for each behavior, the average time spent by low-vocalizing animals was set as one (pink) and the ratio with the time spent by hyper-vocalizing mice shown (red). For example, "Dynamic Interaction" was adopted 2.3 times more frequently by hyper-vocalizing mice than by low-vocalizing animals. (B) Actual values in seconds recorded for each social behavioral trait. ${ }^{* * *} P<0.001$; ${ }^{*} P<0.05$, Mann-Whitney $U$ test).

in the proximal region of DLX5/6, five SNPs (rs12704907, rs4729325, rs1005169, rs1724297, and rs1207733), all located in noncoding regions, that cosegregate at more than $80 \%$ in individuals from the worldwide 1000 Genomes database (The 1000 Genomes Project Consortium), forming a "core" 37,160 bp haplotype (DLX5/6-N-Haplotype) defined by consecutive sites with Neanderthal-like alleles (table 1, fig. 6A). This haplotype includes $D L X 6$ coding and regulatory sequences, the intergenic region between DLX6 and DLX5 and DLX5 intron 3 and exon 3.

To find evidences supporting the DLX5/6-N-Haplotype introgression, we firstly used the introgression probabilities for each SNP reported by Sankararaman, et al. (2014) for all European and all Asian individuals. The average posterior probabilities computed along the putatively introgressed haplotype for Europeans and Asians are equal to 0.0431 and 0.0423 , respectively. Both these values are significantly higher ( $t$-test $P$ value $<2.2 \mathrm{E}-16$ ) than the chromosomal average posterior probability that is equal to 0.0252 for both populations. Moreover, a haplotype (hg38 chr7:96991129-97022094) of Neanderthal (Vindija) origin has been recently identified applying a two-state hidden Markov model to search for archaic fragments (Denisovan, Altai, and Vindija Neanderthal) in the whole genome of the Icelandic population (see Supplementary Materials in Skov, et al. 2020). The identified haplotype corresponds to the DLX5/6-N-Haplotype. Although the DLX5/6-N-Haplotype is the most represented, some of the Icelanders present larger haplotypes which include several additional SNPs of Neanderthal origin. Similarly, in the 1000 Genomes database, the five "core SNPs," present in every population except Africa, cosegregate with other SNPs most of which correspond to those described in Skov et al. (2020) (supplementary table $2 \mathrm{~S}$, Supplementary Material online; supplementary fig. 1S, Supplementary Material online).

Further evidence in favor of introgression is provided by the geographic distribution of archaic-like core haplotypes. The proportion of individuals carrying the DLX5/6-NHaplotype is variable between populations, from $1.5 \%$ in East Asia to $6.3 \%$ in Europe and absent in continental Africa (fig. $6 A$ and $B$ ).

Overall, the proportion of the DLX5/6-N-Haplotype is low in East Asia and America (less than 4\%) and completely absent from Africans and Peruvians from Lima. In South Asia and Europe, the DLX5/6-N-Haplotype is much more frequent reaching up to $8.2 \%$ in the British population of England and Scotland and in Sri Lankan Tamil in the UK. In AfricanAmerican and Caribbean, the haplotype is poorly represented (fig. 6B). The five reported SNPs are in LD in the European populations and the $r^{2}$ are reported in supplementary table 1S, Supplementary Material online for different populations of the 1000 Genomes Project.

To find further evidences in favor of introgression in this genomic area we first determined the haplotype structure of this region (hg38 - chr7:96991129-97022094). We used the inferred 1000 Genomes phase III haplotypes for 2,504 individuals from 26 populations. We reconstructed 5,008 individual haplotypes and 1,020 unique haplotypes. By clustering haplotypes (see Materials and Methods) we identified 5 different clusters (core haplotypes) as reported in figure 6C. We then built a rooted neighbor-joining tree for the region (hg38 - 
A

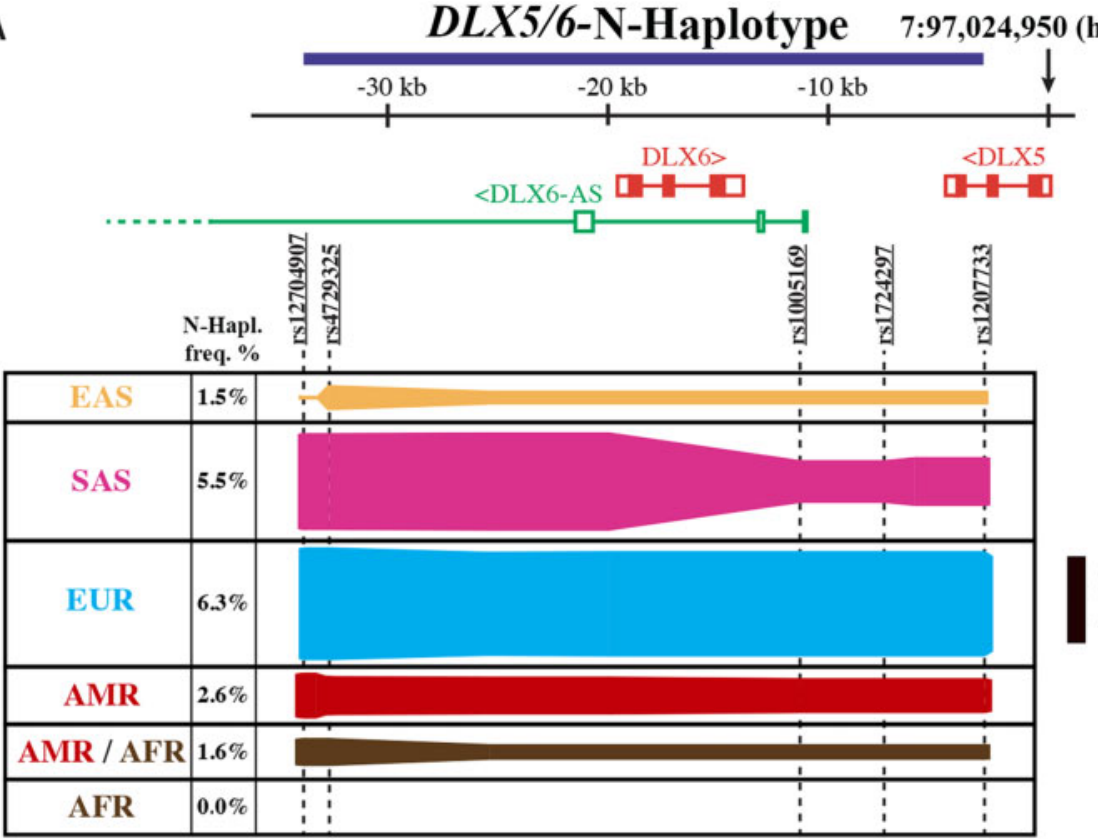

Scale: $\mathbf{5 \%}$

Allelic freq.

B

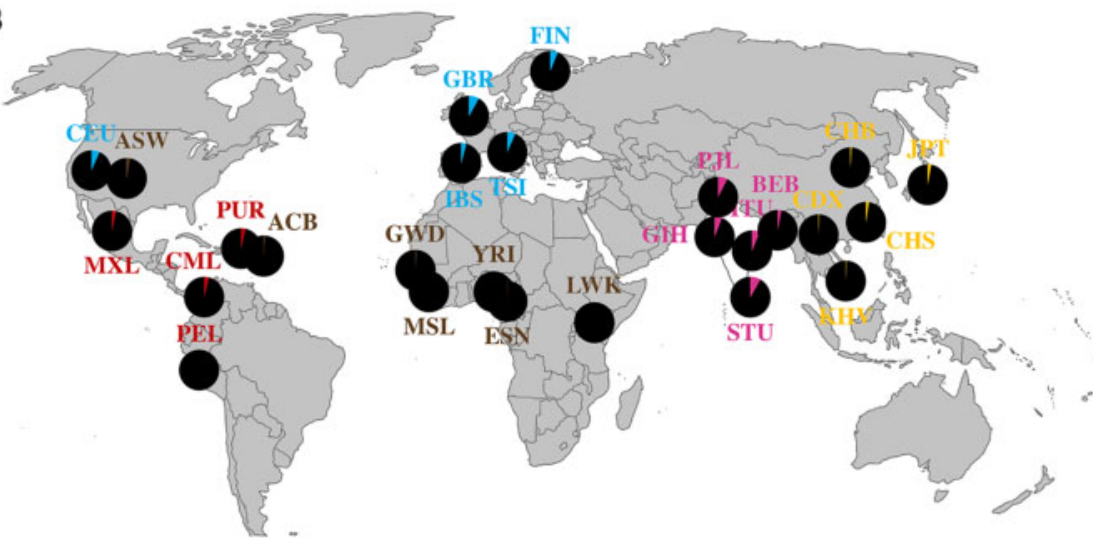

C

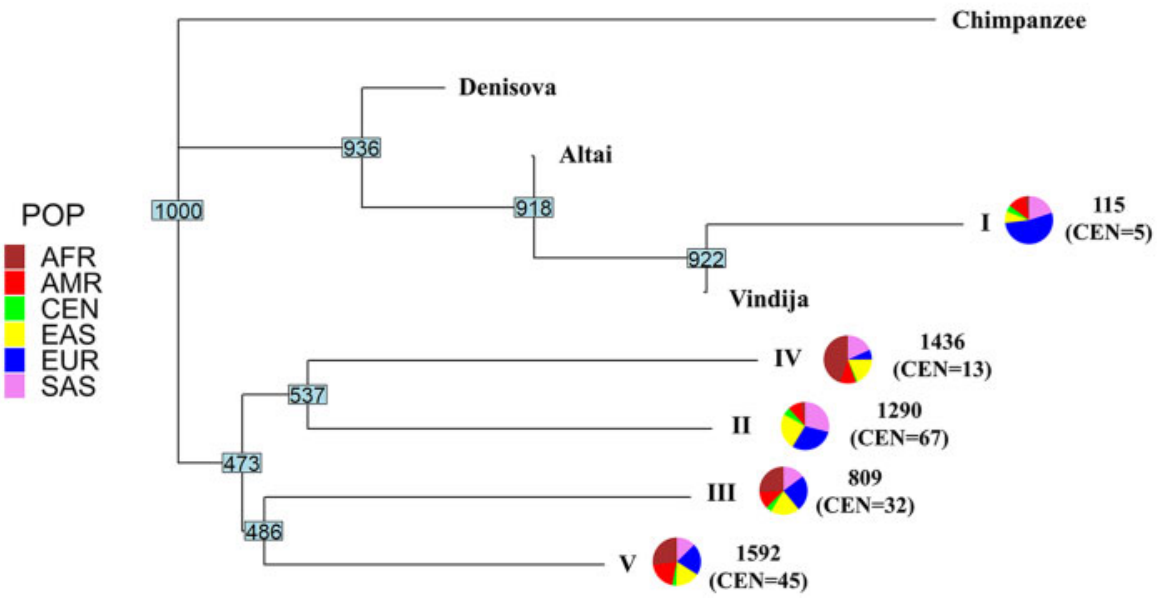

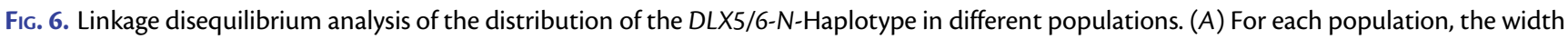
of the color bar represents the allele frequency for each SNP. SNPs linked by a solid bar cosegregate; if cosegregation is less than $100 \%$, the width of the bar diminishes accordingly. The allele frequency of the most represented Neanderthal SNP of the DLX5/6-N-Haplotype is indicated for each population. The major SNPs constituting the haplotype are indicated. The scale bar represents a $5 \%$ allelic frequency within a population. EAS, East Asia populations; SAS, South Asia populations; EUR, European populations; AMR, American populations; AMR/AFR, Afro-americans; AFR, Africans. (B) Geographical distribution of the DLX5/6-N-Haplotype. The allele frequency of the most represented SNP constituting the DLX5/ 6-N-Haplotype is represented on the earth map. The higher frequency of the DLX5/6-N-Haplotype is seen in Europe and South Asia, the haplotype 
Table 1. SNPs Included in the DLX5/6-N-Haplotype.

\begin{tabular}{lcccccccc}
\hline rs_ID & Introgressed & Altai & Vindija & Denisova & Chimp & Bononbo & Gorilla & Orang \\
\hline rs12704907 & C & CC & CC & TT & T & T & T \\
rs4729325 & C & TT & CC & TT & T & T & T \\
rs1005169 & A & CC & CA & CC & C & C & T \\
rs1724297 & A & GG & AG & GG & G & G & C \\
rs1207733 & A & AA & AA & GG & G & G & G & G \\
\hline
\end{tabular}

chr7:96991129-97022094) computing the pairwise genetic distances between the sequences of five modern haplotypes together with the Vindija, Altai, and Denisovan sequences. Branch support values were derived using 1,000 bootstraps (fig. 6C). We included the orthologous sequence for chimpanzee. The analyses showed that haplotype I is the only haplotype similar to the archaic genome sequences and it is the most similar to the Vindija Neanderthal genome.

Haplotype I overlaps with putatively "core" introgressed haplotype (DLX5/6-N-Haplotype) and it is predominantly found in the European individuals (6.3\%) and largely restricted to populations outside Africa. No other modern human haplotypes (II, III, IV, and V) are similar to archaic genomes.

Allele sharing with archaic genomes at polymorphic sites in non-African populations can result either from incomplete lineage sorting or admixture. To distinguish between these two scenarios, we looked at the length of the haplotypes. Introgressed haplotypes present fewer recombinations than those predicted from the time interval that separates modern humans from the common ancestral population. The DLX5/ 6-N-Haplotype is significantly longer than expected under the null hypothesis of incomplete lineage sorting ( $P$ value $=$ $1.08 \mathrm{e}^{-5}$ ), supporting an archaic origin of the haplotype.

\section{Association of the DLX5/6 Locus with Human Cognitive Impairment and Speech Defects}

Deletions or mutations at the DLX5/6 locus are associated with Split Hand Foot Malformation Type 1 (SHFM1), a form of ectrodactyly in which limb malformations can be associated with cognitive, craniofacial, or hearing defects. To evaluate the possible implications of the DLX5/6 locus and of the DLX5/6-N-Haplotype in particular for human development and evolution, we reviewed the cognitive phenotypes reported for SHFM1-patients carrying known genetic alterations within this region (Rasmussen, et al. 2016). This analysis permitted to associate specific genomic subregions to syndromic traits such as mental retardation, language delay, and autism (fig. 7).

Most families carrying mutations limited to the genomic region encompassing only limb-specific enhancers (Birnbaum, et al. 2012) present SHFM1 with no other physical or mental problems, with the exception of one case of mild cognitive defects. Families with deletions or translocations including craniofacial-specific enhancers present SHFM1 with hearing loss with or without other craniofacial anomalies and a high incidence of cognitive defects (Rasmussen, et al. 2016). Large heterozygous deletions covering both regulatory and coding DLX5/6 sequences present SHFM 1 with craniofacial defects associated in 5 out of 7 cases to severe mental retardation. Patients carrying mutations restricted to $D L X 5 / 6$ intergenic region or their coding sequences have a higher probability to include members with ASDs or speech delay but do not present the limb deformities of SHFM1 (Hamilton, et al. 2005; Nakashima, et al. 2010; Poitras, et al. 2010; Chang, et al. 2011).

The DLX5/6-N-Haplotype includes enhancers (156i, 156ii, and MEF2) capable to direct DLX5/6 expression in the brain (Fazel Darbandi, et al. 2016; Assali, et al. 2019). Interestingly, a polymorphism in enhancer $156 \mathrm{i}$ is associated with the binding of GTF2l, a transcription factor deleted in Williams-Beuren syndrome, a complex condition characterized by craniofacial, hyper-vocalization, and hyper-sociability (fig. 7), signs which has been considered an entry point to understand the evolution of the modern human face and prosociability (Zanella, et al. 2019).

Through PheWeb, we examined the association between the SNPs constituting the DLX5/6-N-Haplotype and the phenomes of the Michigan genomics initiative and of the UK Biobank. No significant $P$ values $\left(<5 \times 10^{-8}\right)$ were reported. Results with $P$ values $<0.01$ are reported in supplementary tables 3S-6S, Supplementary Material online.

is not present in African populations and in Peruvians from Lima. CHB, Han Chinese in Beijing, China; JPT, Japanese in Tokyo, Japan; CHS, Southern Han Chinese; CDX, Chinese Dai in Xishuangbanna, China; KHV, Kinh in Ho Chi Minh City, Vietnam; CEU, Utah Residents (CEPH) with Northern and Western European Ancestry; TSI, Tuscans in Italy; FIN, Finnish in Finland; GBR, British in England and Scotland; IBS, Iberian Population in Spain; YRI, Yoruba in Ibadan, Nigeria; LWK, Luhya in Webuye, Kenya; GWD, Gambian in Western Divisions in the Gambia; MSL, Mende in Sierra Leone; ESN, Esan in Nigeria; ASW, Americans of African Ancestry in South-West USA; ACB, African Caribbeans in Barbados; MXL, Mexican Ancestry from Los Angeles USA; PUR, Puerto Ricans from Puerto Rico; CLM, Colombians from Medellin, Colombia; PEL, Peruvians from Lima, Peru; GIH, Gujarati Indian from Houston, Texas; PJL: Punjabi from Lahore, Pakistan; BEB: Bengali from Bangladesh; STU: Sri Lankan Tamil from the UK; ITU, Indian Telugu from the UK. (C) Neighbor-joining tree computed on five modern human haplotypes (I-V) identified through haplotype network analysis, three archaic human haplotypes (Vindija, Denisovan, and Altai) and the chimpanzee. The values in blue boxes represent the support for each branch (1,000 bootstraps). The pie charts point out the frequency in the five continental population groups and in the semi-supercentenarians of each modern human core haplotype. The number reported near each pie-chart indicates the frequency of each core-haplotype among 1000 Genomes individuals and, in brackets, the frequency of the core haplotypes among the semi-supercentenarians. 


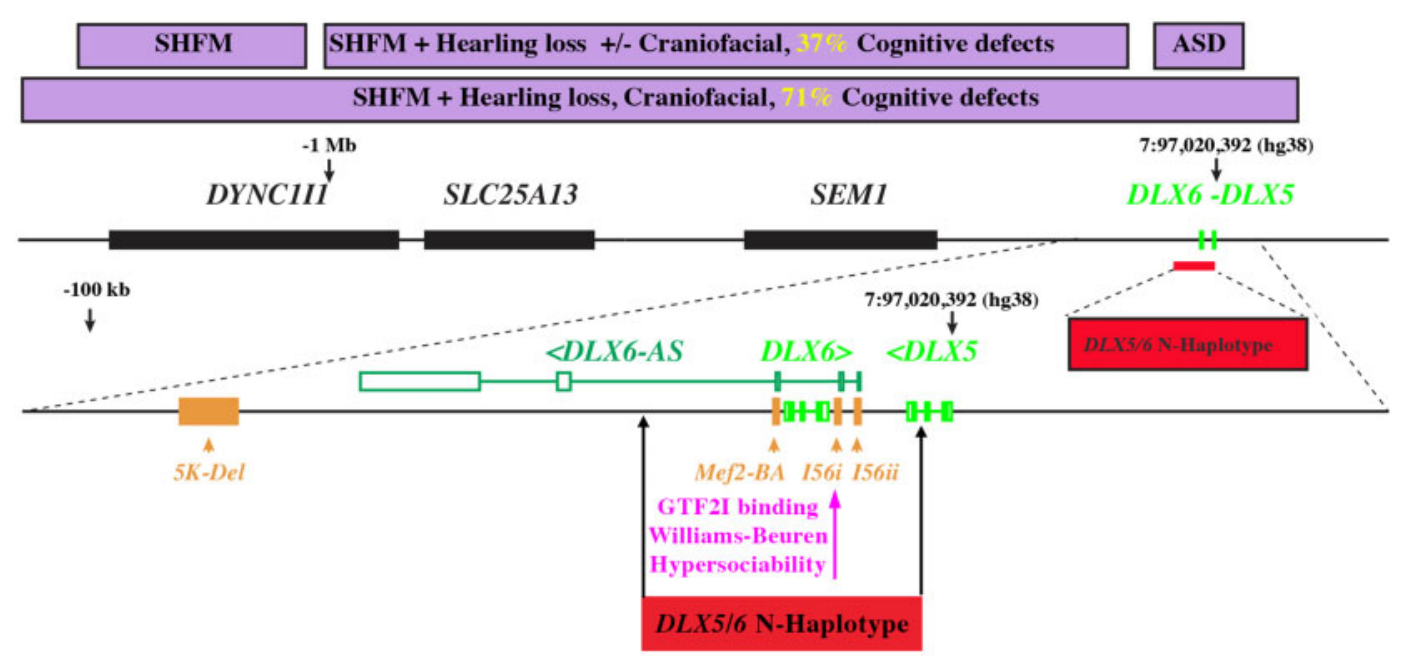

FIG. 7. Association of different pathological conditions with the DLX5/6 genomic region. The central black line represents the $7 q 21.3$ locus, which includes at least 5 genes DLX5, DLX6, SEM1, SLC25A13, and DYNC111. A long noncoding antisense RNA, DLX6-AS, is also transcribed from this region. Purple boxes in the upper part of the figure represent the phenotypic consequences observed in Split Hand Foot Malformation syndrome (SHFM) patients carrying deletion/mutations in this locus. While all SHFM patients present ectrodactyly, in certain cases this malformation is accompanied by craniofacial defects, hearing loss and/or cognitive defects. The closer the deletion are to DLX5/6 coding sequences the higher is the frequency of patients presenting also cognitive impairment. Point mutations within the $D L X 5 / 6$ region and proximal or intragenic enhancers have been associated with autism spectrum disorders (ASD) without ectrodactyly or craniofacial defects and are included in the DLX5/6-N-Haplotype. Three conserved enhancers (156i, 156ii, and Mef2-BA) that direct DLX5/6 expression in the brain (indicated in yellow) are also part of the haplotype. A point mutation within the 156 i enhancer, prevents binding of GTF2I, a transcription factor deleted in Williams-Beuren syndrome, a condition characterized by hyper-vocalization and hyper-sociability (Poitras, et al. 2010).

The GeneATLAS analysis showed that the most significant phenotype is "Standing height" ( $P$ value $=8.92 \mathrm{E}-08$ for rs1207733-G). A detailed list of all phenotypes associated with each SNPs is reported in supplementary tables 7S-11S, Supplementary Material online.

ClinVar, GWAS Catalog, Gwas Central, GTEX PORTAL, and clinGen were examined for the same SNPs, but no results were found. Moreover, we searched if the list of the five variants included in the core haplotype (or variants in LD with those variants) have been previously associated with a trait or disease using the function LDtrait of the R package LDlinkR (Myers, et al. 2020) and no association were reported.

The DLX5/6-N-Haplotype Allele is Under-represented in Semi-supercentenarians

As the DLX5/6 locus has been associated with ASDs and mental retardation (Gandal, et al. 2018 and fig. 7), we analyzed the DLX5/6-N-Haplotype frequency in the MSSNG database of ASDs families (Yuen et al. 2017), and we found a nonsignificant association $(P=0.16)$ with the disease. This finding, however, cannot exclude an association of the haplotype to specific mental traits not necessarily represented in the ASDs database. We then focused on other traits that can be associated with social vocalization. Notably, mortality risk has been correlated to social environment in humans and other social mammals (Snyder-Mackler, et al. 2020). Since inactivation of D/x5/6 in GABAergic neurons results in a 33\% life span extension in mice (de Lombares, et al. 2019), we focused on the population of semi-supercentenarians (CEN), that is people over 105 years of age $(105+)$ characterized by exceptional longevity (Garagnani, et al. 2021). The frequency of the DLX5/
6-N-Haplotype was calculated for all the European populations present in the 1000 Genomes database and estimated for a cohort of 81 Italian semi-supercentenarians. The 105+ (CEN) presented a 50\% under-representation of the haplotype when compared to any other European population with the only exception of IBS, and constituted the most divergent group (fig. 8A).

We found a significant underrepresentation of the DLX5/6$\mathrm{N}$-Haplotype $(P$ value $=0.026)$ in the CEN population when compared to the ITA control group composed by TSI from 1000 Genomes Project and 36 Italian healthy individuals described in Sazzini, et al. (2020). This reduction was also confirmed in the total European population $(P<0.05)$ (fig. $8 A)$.

The same pattern was confirmed for the haplotypes reported in the Neighbor-joining tree (fig. 6C): the frequency of haplotype I (that overlap with DLX5/6-N-Haplotype) in semi-supercentenarians is $3.0 \%$, whereas the frequencies of core haplotypes II, III, IV, and V are $41.4 \%, 19.8 \%, 8.0 \%$, and $27.8 \%$, respectively.

Principal component analysis (PCA) was performed to control for population stratification considering semisupercentenarians and ITA and it shows that the two groups cluster together (supplementary fig. S2A, Supplementary Material online), even if considered in the context of other European populations from 1000 Genomes Project (supplementary fig. S2B, Supplementary Material online).

We also calculated $F_{\text {st }}$ between CEN, ITA, and European populations from 1000 Genomes Project (TSI, GBR, FIN, IBS, and (EEU), considering 110,692 archaic haplotypes located in all chromosomes from Skov, et al. (2020). We performed a distribution of $F_{\mathrm{st}}$ computed between all population pairs 
A
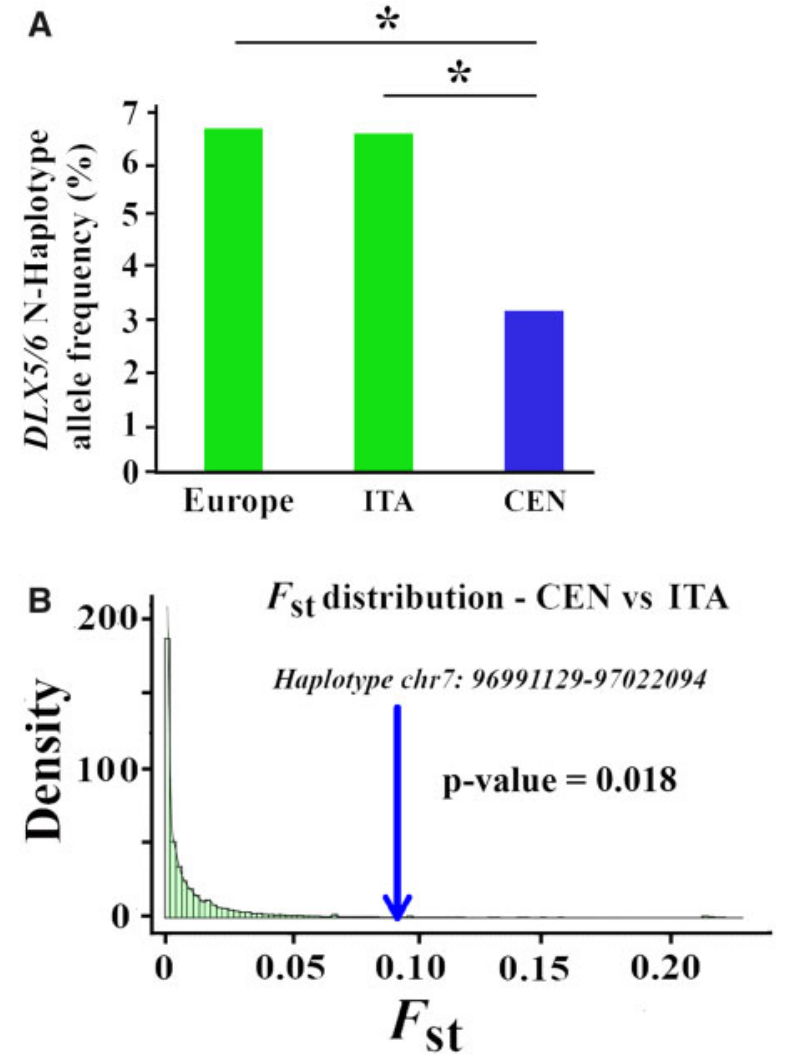

FIG. 8. Allele frequency of the DLX5/6-N-Haplotype in the semi-supercentenarian population. (A) The allele frequency of $D L X 5 / 6-\mathrm{N}$ Haplotype European populations (1000 Genomes Project) is confronted to the CEN population of 81 semi-supercentenarians $(105+$ yo) and to the ITA population (Tuscany 1000 Genomes population $[\mathrm{TSI}]+36$ controls genomes matching the $\mathrm{CEN}$ ). While the ITA population does not show any significant difference from the Europeans, a significant reduction of the DLX5/6-N-Haplotype allele frequency is observed in the semi-supercentenarian population $\left({ }^{*} P<\right.$ $0.05, F_{\text {st }}$ distribution). (B) Density plot build considering all the $F_{\text {st }}$ values calculated considering all the archaic haplotypes described in Skov, et al. (2020) for CEN versus ITA groups. The blue arrow indicates the value of $F_{\text {st }}$ calculated for the DLX5/6-N-Haplotype.

(CEN, ITA and TSI, GBR, FIN, IBS, CEU of 1000 Genomes Project) and for each distribution we checked if the $F_{\text {st }}$ calculated for DLX5/6-N-Haplotype is significantly different from the reported distribution. The comparisons of CEN with ITA showed a significant difference ( $P$ value $=0.018$ ). The difference is still significant ( $P$ value $=0.03$ ) if the same analyses is performed only including low-frequency haplotypes $(<10 \%$ in the ITA group).

The $F_{\text {st }}$ of DLX5/6-N-Haplotype in other comparisons including CEN (CEN vs. FIN, CEN vs. CEU, CEN vs. GBR, and CEN vs. TSI) is always greater than the 90th percentile of the empirical distribution with the only exception of CEN versus IBS. $F_{\text {st }}$ distribution of all archaic haplotypes for CEN versus ITA is reported in figure $8 B$ where the $F_{\text {st }}$ value related to $D L X 5 / 6-\mathrm{N}$-Haplotype is indicated by a blue arrow, suggesting that this haplotype significantly differentiates the two populations $\left(F_{\mathrm{st}}=0.093 ; P\right.$ value $\left.=0.018\right)$. Moreover, to exclude that the identified signal is related to other haplotypes including nonarchaic variants in LD with variants in our region we performed two analyses:

(1) we analyzed haplotypes in the surrounding regions selecting haplotypes that include nonarchaic variants in even weak LD with our archaic variants (downstream our region hg38: chr7:96,991,129-97,022,094);

(2) we analyzed a new haplotype built with six non-archaic variants in $\operatorname{LD}\left(r^{2}>0.7\right)$ with all the archaic variants within the analyzed region (hg38: chr7:96,991,129$97,022,094)$.

First, we performed a LD analyses of the area to identify all the SNPs in LD with archaic variants (we reported in supplementary fig. 3S, Supplementary Material online a map with pattern of LD in the ITA population, measured by the $R^{2}$ statistic including a wide region around DLX5/6-NHaplotype). Archaic-variants are in weak LD with nonarchaic variants located downstream. These variants define two non-archaic haplotypes (indicated with green and red segments in supplementary fig. 3S, Supplementary Material online). We thus computed the $F_{\mathrm{st}}$ values between CEN and ITA for both the non-archaic haplotypes $\left(F_{s t}=0.006\right.$ and $F_{\mathrm{st}}=0.005$, respectively), and we checked if the calculated $F_{\text {st }}$ values are significant from the reported $F_{\text {st }}$ distribution. No significant $P$ values were observed $(P$ value $=0.364$ and $P$ value $=0.382$, respectively), supporting the relevance of inferences on this specific haplotype.

Secondly, we selected all the nonarchaic variants in LD $\left(r^{2}>0.7\right)$ with all the archaic variants in the same region (segment in blue in supplementary fig. 3S, Supplementary Material online) and we calculated $F_{\text {st }}$ between CEN and ITA that is 0.073 ( $P$ value $=0.029)$, lower than the $F_{\text {st }}$ computed for the archaic variants. These results suggest that the larger $F_{\mathrm{st}}$ effect is observed for the haplotype defined by the archaic variants.

\section{Discussion}

Here, we have shown that reduction of $D L X 5 / 6$ expression in mouse GABAergic neurons results in a hyper-vocalization and hyper-socialization phenotype. Furthermore, we identified a DLX5/6-Neanderthal-derived haplotype present in up to $8 \%$ of non-African alleles that includes enhancers controlling gene expression in the central nervous system (Fazel Darbandi, et al. 2016) and sequences associated with either hyper- or hypo-socialization/vocalization pathologies such as Williams-Buren syndrome (Poitras, et al. 2010) or ASDs (Gandal, et al. 2018). Interestingly, the DLX5/6-N-Haplotype is underrepresented in the genomes of healthy semisupercentenarians suggesting an association between DLX5/ 6 brain expression and healthy aging reminiscent of what has been shown in mouse models (de Lombares, et al. 2019).

In social mammals, such as mice and humans, vocal communication is essential for the survival of the group. It is needed to convey diverse information such as location, social status, reproductive availability, emotional context (fear, aggression), food availability, and presence of predators. Such a 
vast set of inputs and outputs is coordinated by a complex neural network that combines regions of the forebrain, of the basal ganglia and of the brainstem (Jurgens 2002). A key brain region involved in the integration of these neuronal activities is the periaqueductal gray (PAG), a midbrain territory that receives multiple telencephalic inputs and transmit them to phonation and respiration motor centers. As D/x5/6 are not expressed in the PAG, but only in telencephalic interneurons, their effect on vocalization must derive from cognitive initiation and modulation and not from impairment of laryngeal or respiratory motor centers.

In comparison to their normal controls, many D/ $\times 5 / 6^{\text {VgatCre }}$ and D/x5/6 $\mathrm{V}^{\mathrm{gaCre} /+}$ mice emit a higher number of longer "complex" calls often not separated by any interruption. These long-modulated USVs are emitted prevalently when mice are engaged in socially intense behaviors and more rarely during isolated behavior (Ey, et al. 2020). Therefore, the highvocalization profile of D/ $\times 5 / 6^{\text {VgatCre }}$ mice is predictive of an enhanced social behavior and is in line with our finding of an increase in dynamic socialization of high-vocalizing individuals.

Many mouse models have been generated to study the effects of genetic lesions associated with human neurodevelopmental disorders. In particular, the simultaneous study of ultrasonic vocalizations and behavior has permitted to evaluate the impact of specific mutations on social communication and interaction in mouse models of ASDs (Caruso, et al. 2020). For example, female-female social interactions and USV have been analyzed in Shank $2^{-/-}$and Shank $3^{-/-}$mutant mice showing reduction in the number and duration of USVs associated with diminished sociability (Schmeisser, et al. 2012; Ey, et al. 2013; Wohr 2014). Extrapolation of our results to the human condition would suggest that reduced $D L X 5 / 6$ expression in GABAergic neurons could be associated with increased social vocalization, a phenotype opposite to ASDs.

Our understanding of the origin of psychiatric pathologies such as schizophrenia and ASDs has recently progressed substantially thanks to large genome-wide association studies (GWAs). They have shown that, beyond some specific cases where monogenic mutations cause highly penetrant phenotypes, psychiatric conditions are complex polygenic disorders associated with hundreds of common genetic loci involving genes often associated with synaptic function and neural development (Huguet, et al. 2016; Dennison, et al. 2020). Module analyses of gene-networks implicated in interneuron-dependent ASD and schizophrenia have identified gene expression variations and splicing of DLX5, DLX6, and asDLX6nc. Indeed, the modules including these $D L X$ genes and other key genetic components of GABAergic neurons constitute the major hub for both ASD and schizophrenia (Gandal, et al. 2018). Remarkably, a point mutation within the $156 i$ enhancer is associated with binding of the transcription factor GTF2l, which is deleted in Williams-Beuren syndrome characterized by hyper-vocalization and hypersociability (Poitras, et al. 2010).

GTF2l is located in 7q11.23, a genomic region which deletion or microduplication provokes complex syndromes with opposite social and speech language behaviors including sociability, speech language, and cognitive alteration associated with neural crest-associated facial features (LópezTobón, et al. 2020). These genetic networks, which include DLX5/6 and control concomitant modifications of craniofacial morphology, cognition, and sociability are proposed to have contributed to human self-domestication (Zanella, et al. 2019). Furthermore, DLX5/6 were proposed as potential contributors to brain and skull globularization and acquisition of human-specific language capacities (Boeckx and BenitezBurraco 2014a).

The origin of vocal language in the genus Homo has been approached through anatomical analyses of the brain and larynx and, more recently, through the comparison of genes involved in language acquisition such as FOXP2 (Dediu and Levinson 2013; Dediu and Christiansen 2016). Remarkably, FOXP2 is located in 7q31, close to the DLX5/6 locus (7q21), and regulates the expression of a large antisense noncoding RNA of DLX6 (asDLX6nc or Evf1/2) (Vernes, et al. 2006, 2011), which is directly involved in the control of D/x5 and D/x6 expression (Feng, et al. 2006).

The DLX5/6-N-Haplotype covers the complete sequence of $D L X 6$, the $D L X 5 / 6$ intergenic region, the second intron and third exon of $D L X 5$, three known enhancers for brain expression of DLX5/6: 156i, 156ii, and Mef2-BA (Birnbaum, et al. 2012), and the three first exons of the long noncoding RNA asDLX6nc, which has been implicated in GABAergic neuronal differentiation (Cajigas, et al. 2018). The major SNPs composing the DLX5/6-N-Haplotype are located in noncoding sequences in proximity of the known enhancers and splice sites of DLX5 and asDLX6nc and could well alter their expression profile.

Whole-genome analyses of Neanderthal and Denisovan introgressions in 27,566 Icelanders identify the presence of DLX5/6-N-Haplotype comprising the five core SNPs with a $1.8 \%$ allelic frequency identified as having a Neanderthal origin. This introgression coexists with other, rare, longer haplotypes (Skov, et al. 2020).

The comparison of human genomes with those of other vertebrate species and, in particular, with other Hominidae, has revealed the presence of Human Accelerated Regions (HARs), short sequences presenting an important number of Single Nucleotide Changes (SNCs) specific to $H$. sapiens (Lindblad-Toh, et al. 2011; Capra, et al. 2013). Interestingly, the DLX5/6 locus includes at the same time 5 HARs and, as shown in this report, an introgressed Neanderthal region.

This paradoxical situation might suggest that enhancers implicated in nonneural functions of DLX5/6 such as bone remodeling and reproduction could have been strongly counter-selected, whereas brain-expression driving enhancers could have been conserved in the human population. Interestingly, two of these HARS are located immediately in $5^{\prime}$ from DLX5/6-N-Haplotype (2.1 and $3.1 \mathrm{~kb}$ ), whereas the other three are more distant $(81.5,634,1088 \mathrm{~kb}$ upstream although in the range of the multiple known modifiers of DLX5/6 expression). The presence of the proximal HARs may have limited the extension of the introgressed haplotype in $5^{\prime}$. 
Vocal communication and socialization are pivotal traits of the evolution of modern human society. The conservation of the DLX5/6-N-Haplotype in 6.3\% of EUR alleles (which represent about $12.6 \%$ of the population as the DLX5/6-NHaplotype is almost invariably heterozygous), might have contributed to the sustainability of modern human society. The analyses of the phenotype/genotype associations which we have performed using UK Biobank and other platforms (supplementary tables 3-11, Supplementary Material online) present fairly high $P$ values and do not permit to draw, at present, any solid correlation. As DLX5/6 are pleiotropic genes with multiple interconnected functions including craniofacial morphogenesis, neuronal differentiation, bone development, and reproduction (Merlo, et al. 2000) one could speculate that the presence of the DLX5/6-N-Haplotype might also affect other traits characteristic of the evolution of $\mathrm{H}$. sapiens, such as metabolism, skull shape and bone density. In particular, one of the main differences between modern humans and Neanderthals has been the composition and size of social groups: while Neanderthal groups were small, composed of 10-30 individuals, modern humans developed complex societies (Duveau, et al. 2019). It is possible, therefore, that the DLX5/6-N-Haplotype could influence characters affecting the structure of modern human society.

However, the DLX5/6-N-Haplotype seems to correlate with different aspects of human health in modern human populations and some of them are pathological conditions. This observation is in line with data that demonstrates that a high proportion of Neanderthal introgression might be deleterious for modern humans (Juric, et al. 2016). Thus, we can speculate that the frequency of this haplotype in the modern human population was the result of balancing selection shaped by different evolutionary forces. Future studies are needed to address this point.

Interestingly, the DLX5/6-N-Haplotype is underrepresented in semi-supercentenarians, a population considered as a paradigm of healthy aging as it has the capacity to slow the progression of pathological conditions determining reduced mental and physical functions (Vacante, et al. 2012).

This observation could be related to the 33\% lifespan extension described for D/x5/6 ${ }^{\text {VatCre }}$ mice, suggesting that the DLX5/6-N-Haplotype could regulate DLX5/6 neuronal expression (de Lombares, et al. 2019). These data on semisupercentenarians could be seen in the light of George Williams antagonistic pleiotropy theory (Williams 1957), who proposes that genes controlling more than one phenotypic trait can have been positively selected being favorable early in life and in adulthood but can become detrimental later in life (old age and extreme longevity), phases of life subjected to weaker evolutionary pressures (Williams 1957; De Benedictis and Franceschi 2006; Giuliani, et al. 2017).

Our findings could well be integrated within current ideas on the biology of aging which suggest that aging rates, and consequently lifespans, evolve as a function of trade-offs with other characters including social, cognitive, and reproductive capacities (Yang, et al. 2016; Giuliani, et al. 2018; SnyderMackler, et al. 2020).

\section{Materials and Methods}

\section{Animals}

Procedures involving animals were conducted in accordance with European Community and French Ministry of Research directives. The project was reviewed and approved by the "Cuvier" ethical committee of the MNHN (CEEA Cuvier $\mathrm{n}^{\circ} 68$ ) and validated by the French Ministry of Research (ref. 3917).

Mice were housed in light, temperature, and humiditycontrolled conditions. Food and water were available ad libitum. Mice were individually identified by a microchip implanted 3 weeks postnatal. Litter sizes and genotypes were kept in record. D/x5/6 $6^{\text {VatCre/+ }}$ and D/x5/6 VgatCre mice, were generated using a Cre/lox strategy to simultaneously remove D/x5/6 homeodomain-coding sequences specifically in GABAergic neurons (de Lombares, et al. 2019): Dlx5/6 flox/flox mice (Bellessort, et al. 2016) were crossed with SIc32a ${ }^{\text {tm2 (cre)Lowl }}$ knock-in mice (here referred to as Vgat ${ }^{\text {cre/+ }}$ mice) in which the "Cre-recombinase" gene is expressed only by GABAergic neurons on a mixed C57BL6/N X DBA/2 genetic background. Phenotypes of Dl $\times 5 / 6^{\text {VgatCre/+ }}$ and Dl $\times 5 / 6^{\text {VgatCre }}$ mice were compared to those of control littermates.

\section{Vocalization and Social Behavior Analysis}

Test females were isolated 3 days before the trial to increase their motivation for social interactions. On trial day, the tested female mouse was placed in a test cage (Plexiglas, $50 \mathrm{~cm} \times 25 \mathrm{~cm} \times 30 \mathrm{~cm}$, 100 lux, with fresh bedding) for $30 \mathrm{~min}$ habituation. After this time, an unfamiliar grouphoused control adult female was introduced. Ultrasonic vocalizations were recorded with a condenser ultrasound microphone Polaroid/CMPA, the interface UltraSoundGate 416200, and the software Avisoft-SASLab Pro Recorded from Avisoft Bioacoustics (sampling frequency: $300 \mathrm{kHz}$; FFTlength: 1024 points; 16-bit format). Ultrasonic vocalizations were recorded for the pair of mice tested (one control newcomer and a habituated control, Dl $\times 5 / 6^{\text {VgatCre/+ }}$ or Dl $\times 5 /$ $6^{\text {VgatCre }}$ mouse). All analyzed animals were 6 months old. Previous studies suggest that the contribution of the newcomer to the vocalization is minor in comparison with that of the occupant (Hammerschmidt, et al. 2012). We measured the latency for the first ultrasonic vocalizations and the total number of ultrasonic vocalizations emitted. We manually established the distribution of ultrasonic vocalizations among the following call types (see Ey, et al. 2013): 1) short, call duration less than $5 \mathrm{~ms} ; 2$ ) simple, call duration longer than $5 \mathrm{~ms}$ and a frequency range either smaller than $6.25 \mathrm{kHz}(\mathrm{sim}$ ple flat) or with a frequency modulation in only one direction (simple upward or downward); 3) complex, frequency modulations in more than one direction and frequency range larger than $6.25 \mathrm{kHz}$ (modulated), or inclusion of one or more additional frequency components (harmonic or nonlinear phenomena, but no saturation); 4) unstructured, no pure tone component and 5) frequency jumps, presence of one or more jump(s) in frequency, without time gap between the consecutive elements. 
We used unpaired nonparametric Wilcoxon tests to compare the latency for the first call and the call rate between genotypes. We used $\chi^{2}$ (with a Bonferroni correction for multiple testing) tests to compare the proportions of calls between genotypes.

During vocalization analysis, animals were filmed for $10 \mathrm{~min}$. Social behavior was measured using a real-time approach that couples computer vision, machine learning, and triggered-RFID identification to track and monitor animals (de Chaumont, et al. 2019).

\section{Histological Analysis}

Mice were fixed by transcardiac perfusion with $4 \%$ paraformaldehyde, brains were cryoprotected in 30\% sucrose and frozen. Cryoprotected brains were embedded in OCT (Leica, France) and 60- $\mu \mathrm{m}$-thick free-floating cryostat sections were prepared.

For lacZ expression analysis, X-gal staining was performed as described (Acampora, et al. 1999) on sections from Dl $\times 5^{\text {lacz/+ }}$ brains. Pictures were acquired using a light microscope.

\section{Identification of DLX5/6-Neanderthal Haplotype Introgression}

To investigate whether polymorphisms identified in the DLX5/6 locus belong to a Neanderthal introgressed haplotype, we analyzed individuals from the 1000 Genomes data set (The 1000 Genomes Project Consortium phase 3, 2015) and looked for Neandertal-like alleles in a window of $200 \mathrm{~kb}$ up and downstream from DLX5, using continental African populations as outgroup. Among these SNPs, we identified an haplotype of 37,160 bp (GRCh 38-7: 96,991,12997,022,094) defined by five consecutive SNPs (rs12704907, rs4729325, rs1005169, rs1724297, rs1207733) with Neandertal-like alleles shared by at least $80 \%$ of individuals worldwide.

To explore the relationship between haplotypes in this genomic region (Hg38: chr7:96991129-97022094), we constructed a haplotype network based on the haplotypes of all 1000 Genomes individuals (phase III). We used 654 SNPs where archaic genomes were homozygous. We used SHAPEIT to phase together the haplotypes of the 2,504 individuals from 1,000 Genomes, the haplotypes of the 81 semi-super centenarians, and the haplotypes of the 36 matched controls. We identified 5,242 individual haplotypes and 1,020 unique haplotypes. We merged the resulting 1020 unique modern haplotypes into five different clusters (core haplotypes) using an AGlomerative NESting hierarchical cluster analysis (AGNES), implemented in the $\mathrm{R}$ package cluster (Maechler 2019). The optimal number of clusters was defined using the silhouette method (Rousseeuw 1987). The mean pairwise nucleotide difference observed in each group is less than 12 , whereas the mean pairwise nucleotide difference between each group exceeds 12 . We generated a consensus sequence for each core haplotype, corresponding to the sequence of the allele with the highest frequency in each cluster. Then, we computed a rooted neighbor-joining tree for the entire $30.96 \mathrm{~kb}$ region based on the nucleotide distance between the sequences of the five modern human core haplotypes together with the Altai, Denisovan, Vindija, chimpanzee (outgroup of the tree) using the $\mathrm{R}$ package ape (Paradis and Schliep 2019).

We computed the probability of generating such a long haplotype under a scenario of incomplete lineage sorting by assuming the haplotype length follows a gamma distribution (Huerta-Sanchez, et al. 2014) using the parameters from (Dannemann, et al. 2016) and the local recombination rate of $2.046 \mathrm{cM} / \mathrm{Mb}$ (Hinch, et al. 2011). The haplotype is significantly longer than expected under the null hypothesis of incomplete lineage sorting $\left(P\right.$ value $=1.08 \mathrm{e}^{-05}$ ), supporting an Archaic origin. The DLX5/6-N-Haplotype covers part of $D L X 5$, all $D L X 6$, the intergenic region, and regulatory region upstream of DLX6. The proportion of each SNP in the different geographic regions was derived from the 1000 Genomes database phase 3, which included 694 American, 1,008 EastAsian, 1,006 European, 978 South-Asian, and 1,322 African genomes.

\section{DLX5/6-N-Haplotype Allelic Frequency}

The allelic frequency of each SNP composing the DLX5/6-NHaplotype and their linkage disequilibrium was determined in populations of different geographical and ethnical origins present in the 1000 Genomes data set (The 1000 Genomes Project Consortium 2015). These frequencies were used to reconstruct the haplotype using the linkage disequilibrium $R^{2}$ between the different SNPs; their variations suggested the coexistence of several haplotypes of different sizes (unphased reconstruction). Genome-wide phased data (Skov, et al. 2020) also identified the introgression of the DLX5/6-N-Haplotype and the other haplotypes of different size from Neanderthal. We searched if the list of the 5 variants included in the core haplotype (or variants in LD with those variants) have been previously associated with a trait or disease using the function LDtrait of the R package LDlinkR (Myers, et al. 2020) (https:// cran.r-project.org/web/packages/LDlinkR/index.html) setting $r^{2}$ of LD $>0.1$ in the Europeans and a window of $500,000 \mathrm{bp}$. No association was reported excluding the presence of non-archaic variants with phenotypic effects in the neighborhood.

DLX5/6-N-Haplotype representation in autistic populations was determined using the MSSNG database (Yuen et al. 2017) and the probability was calculated by transmission disequilibrium test (TDT).

PheWeb was examined to identify phenotypes associated with the five SNPs (rs12704907, rs4729325, rs1005169, rs1724297, and rs1207733) (Gagliano Taliun, et al. 2020). We examined UK Biobank data set through PheWeb based on SAIGE analysis of ICD -derived traits (http://pheweb.sph. umich.edu/SAIGE-UKB/) (Zhou, et al. 2018) and on the first Neale lab analysis (https://pheweb.org/UKB-Neale/). PheWeb was examined to identify associations considering participants of the Michigan Genomics Initiative (http://pheweb. org/MGl-freeze2/). PhenoScanner v2 (http://www.phenoscanner.medschl.cam.ac.uk/), ClinVar (https://www.ncbi.nlm. nih.gov/clinvar/), GWAS Catalog (https://www.ebi.ac.uk/ gwas/), Gwas Central (https://www.gwascentral.org/), GTEX 
Portal (https://gtexportal.org/home/), and clinGen (https:// clinicalgenome.org/) were examined to identify in silico potential functional impact of the five SNPs (rs12704907, rs4729325, rs1005169, rs1724297, and rs1207733). Then, we analyzed phenotypic associations in the UK Biobank using the GeneATLAS tool (Canela-Xandri, et al. 2018). In brief, the Gene ATLAS provides phenotypic associations based on Mixed Linear Models using 452,264 Britons with European descent. The model includes sex, array batch, UK Biobank Assessment Centre, age, and 20 genomic principal components. Results are reported in supplementary tables 7S-11S, Supplementary Material online).

The genomes from a cohort of 81 healthy semisupercentenarians and supercentenarians [105+/110+] older than 105 years (mean age 106.6 \pm 1.6 ) recruited in North, Center, and South of the Italian peninsula (CEN) were compared to a population (ITA) obtained combining the Tuscany 1000 Genomes population (TSI) with 36 controls genomes matching the different geographical origin of CEN. European population correspond to TSI, CEU, FIN, GBR, and IBS people present in 1000 Genomes. Haplotypes were used to compute the $F_{\text {st }}$ statistic (Nei 1973) between all the combinations of population pairs. To evaluate the significance of the $F_{\mathrm{st}}$ observed values, we performed 500 simulations where individuals were randomly assigned to one of the seven studied populations. For each simulation, $F_{\text {st }}$ statistic was computed. At the end of this procedure, we were able to fit a probability density function for the $F_{\text {st }}$ statistic and to compute an empirical $P$ value for the $F_{\text {st }}$ using the GHap (Utsunomiya, et al. 2016) R package. The significance of allelic differences between European population and semisupercentenarians was also determined with a $\chi^{2}$ test.

In order to test if the $F_{\text {st }}$ calculated for the $D L X 5 / 6-\mathrm{N}$ Haplotype is within the distribution of other archaic haplotypes or is an outlier, we built a density plot considering all the $F_{\text {st }}$ values calculated including all the 110,692 archaic haplotypes described by Skov, et al. (2020) for CEN versus ITA groups. The 110,692 archaic haplotypes (Skov, et al. 2020) are located on all chromosomes and were phased by applying SHAPEIT software v.2.17 (Delaneau, et al. 2013; O'Connell, et al. 2014). For each archaic haplotype, the $F_{\text {st }}$ statistic (Nei 1973) was computed between all population pairs (CEN, ITA and CEU, FIN, GBR, and IBS from 1000 Genomes Project). Then, for each pairwise comparison, we fitted a probability density function for the $F_{\text {st }}$ statistic and an empirical $P$ value was computed for the $F_{\mathrm{st}}$ value calculated on our haplotype.

To explore the extent of the DLX5/6-N-Haplotype, we computed the Linkage Disequilibrium (LD) between 278 SNPs (MAF $>0.05$ in ITA) located in a wide region (hg38 chr7:96935616-97130527) encompassing the DLX5/6-NHaplotype (supplementary fig. 3S, Supplementary Material online). We defined two haplotypes (indicated with green and red segments in supplementary fig. 3S, Supplementary Material online) using the -blocks flag of the software PLINK (Purcell, et al. 2007). These haplotypes include nonarchaic variants in weak $L D$ with archaic variants and located downstream the core-haplotype. We computed the $F_{\text {st }}$ value between CEN and ITA for such defined nonarchaic haplotypes, and we checked if the calculated $F_{\text {st }}$ value is significant from the reported $F_{\text {st }}$ distribution. The same $F_{\text {st }}$ analysis was then performed considering nonarchaic variants included in the core-haplotype (indicated with the blue segment in supplementary fig. 3S, Supplementary Material online) and in high $\operatorname{LD}\left(r^{2}>0.7\right)$ with all the archaic variants present in the same region. The $F_{\text {st }}$ analysis was implemented in $\mathrm{R}$ software (https://www.R-project.org/) using the GHap package (Utsunomiya, et al. 2016).

\section{Supplementary Material}

Supplementary data are available at Molecular Biology and Evolution online.

\section{Acknowledgments}

This research was partially supported the ANR grants TARGETBONE (ANR-17-CE14-0024) and METACOGNITION (ANR-17-CE37-0007) to GL, grants of the "Fondation-NRJ-Institut de France" ( ${ }^{\circ}$ 216612) and the ATM "Cognitio" to NNN, CdL was supported by a grant of the French Ministry of Research. We thank the following researchers for their valuable input: Dr Stéphane Peyregne, Department of Evolutionary Genetics, Max Planck Institute for Evolutionary Anthropology, Leipzig, Germany for initial analysis of the DLX5/6-N-Haplotype. Drs Thomas Bourgeron, Elodie Ey, and Fabrice de Chaumont from the Pasteur Institute, Paris, for initial analysis of the vocalization and behavioral data. Dr Robbie Davies from The Centre for Applied Genomics, Toronto, Canada for analysis of the association between the DLX5/6$\mathrm{N}$-Haplotype and autism in the MSSNG database. A particular thank goes to the team in charge of mouse animal care and in particular M. Stéphane Sosinsky and M. Fabien Uridat and to Pr. Amaury de Luze in charge of the "Cuvier" ethical committee. We thank Ms Aicha Bennana and Lanto Courcelaud for administrative assistance.

\section{Data Availability}

The data underlying this article are available on reasonable request.

\section{References}

Acampora D, Merlo GR, Paleari L, Zerega B, Postiglione MP, Mantero S, Bober E, Barbieri O, Simeone A, Levi G. 1999. Craniofacial, vestibular and bone defects in mice lacking the distal-less-related gene Dlx5. Development 126(17):3795-3809.

Assali A, Harrington AJ, Cowan CW. 2019. Emerging roles for MEF2 in brain development and mental disorders. Curr Opin Neurobiol. 59:49-58.

Bell JT, Tsai PC, Yang TP, Pidsley R, Nisbet J, Glass D, Mangino M, Zhai G, Zhang F, Valdes A, et al.; MUTHER Consortium. 2012. Epigenomewide scans identify differentially methylated regions for age and agerelated phenotypes in a healthy ageing population. PLoS Genet. 8(4):e1002629.

Bellessort B, Le Cardinal M, Bachelot A, Narboux-Neme N, Garagnani P, Pirazzini C, Barbieri O, Mastracci L, Jonchere V, Duvernois-Berthet E, et al. 2016. Dlx5 and Dlx6 control uterine adenogenesis during postnatal maturation: possible consequences for endometriosis. Hum Mol Genet. 25(1):97-108. 
Beverdam A, Merlo GR, Paleari L, Mantero S, Genova F, Barbieri O, Janvier P, Levi G. 2002. Jaw transformation with gain of symmetry after Dlx5/Dlx6 inactivation: mirror of the past? Genesis 34(4):221-227.

Birnbaum RY, Everman DB, Murphy KK, Gurrieri F, Schwartz CE, Ahituv N. 2012. Functional characterization of tissue-specific enhancers in the DLX5/6 locus. Hum Mol Genet. 21(22):4930-4938.

Boas F. 1938. The mind of primitive man. New York: Macmillan.

Boeckx C, Benitez-Burraco A. 2014a. Globularity and language-readiness: generating new predictions by expanding the set of genes of interest. Front Psychol. 5:1324.

Boeckx C, Benitez-Burraco A. 2015. Osteogenesis and neurogenesis: a robust link also for language evolution. Front Cell Neurosci. 9:291.

Boeckx C, Benitez-Burraco A. 2014b. The shape of the human languageready brain. Front Psychol. 5:282.

Cajigas I, Chakraborty A, Swyter KR, Luo H, Bastidas M, Nigro M, Morris ER, Chen S, VanGompel MJW, Leib D, et al. 2018. The Evf2 ultraconserved enhancer IncRNA functionally and spatially organizes megabase distant genes in the developing forebrain. Mol Cell. 71(6):956-972 e959.

Canela-Xandri O, Rawlik K, Tenesa A. 2018. An atlas of genetic associations in UK Biobank. Nat Genet. 50(11):1593-1599.

Capra JA, Erwin GD, McKinsey G, Rubenstein JL, Pollard KS. 2013. Many human accelerated regions are developmental enhancers. Philos Trans R Soc Lond B Biol Sci. 368(1632):20130025.

Caruso A, Ricceri L, Scattoni ML. 2020. Ultrasonic vocalizations as a fundamental tool for early and adult behavioral phenotyping of Autism Spectrum Disorder rodent models. Neurosci Biobehav Rev. 116:31-43.

Chang SC, Pauls DL, Lange C, Sasanfar R, Santangelo SL. 2011. Common genetic variation in the GAD1 gene and the entire family of DLX homeobox genes and autism spectrum disorders. Am J Med Genet $B$ Neuropsychiatr Genet. 156(2):233-239.

Cho KK, Hoch R, Lee AT, Patel T, Rubenstein JL, Sohal VS. 2015. Gamma rhythms link prefrontal interneuron dysfunction with cognitive inflexibility in Dlx5/6(+/-) mice. Neuron 85(6):1332-1343.

Conte D, Garaffo G, Lo lacono N, Mantero S, Piccolo S, Cordenonsi M, Perez-Morga D, Orecchia V, Poli V, Merlo GR. 2016. The apical ectodermal ridge of the mouse model of ectrodactyly Dlx5;Dlx6-/shows altered stratification and cell polarity, which are restored by exogenous Wnt5a ligand. Hum Mol Genet. 25(4):740-754.

Crackower MA, Scherer SW, Rommens JM, Hui CC, Poorkaj P, Soder S, Cobben JM, Hudgins L, Evans JP, Tsui LC. 1996. Characterization of the split hand/split foot malformation locus SHFM1 at 7q21.3-q22.1 and analysis of a candidate gene for its expression during limb development. Hum Mol Genet. 5(5):571-579.

Dannemann M, Andres AM, Kelso J. 2016. Introgression of Neandertaland Denisovan-like haplotypes contributes to adaptive variation in human toll-like receptors. Am J Hum Genet. 98(1):22-33.

De Benedictis G, Franceschi C. 2006. The unusual genetics of human longevity. Sci Aging Knowledge Environ. 2006(10):pe20.

de Chaumont F, Ey E, Torquet N, Lagache T, Dallongeville S, Imbert A, Legou T, Le Sourd AM, Faure P, Bourgeron T, et al. 2019. Real-time analysis of the behaviour of groups of mice via a depth-sensing camera and machine learning. Nat Biomed Eng. 3(11):930-942.

de Lombares C, Heude E, Alfama G, Fontaine A, Hassouna R, Vernochet C, de Chaumont F, Olivo-Marin C, Ey E, Parnaudeau S, et al. 2019. Dlx5 and Dlx6 expression in GABAergic neurons controls behavior, metabolism, healthy aging and lifespan. Aging (Albany NY)). 11(17):6638-6656.

Dediu D, Christiansen MH. 2016. Language evolution: constraints and opportunities from modern genetics. Top Cogn Sci. 8(2):361-370.

Dediu D, Levinson SC. 2013. On the antiquity of language: the reinterpretation of Neandertal linguistic capacities and its consequences. Front Psychol. 4:397.

Delaneau O, Zagury JF, Marchini J. 2013. Improved whole-chromosome phasing for disease and population genetic studies. Nat Methods. 10(1):5-6.
Dennison CA, Legge SE, Pardinas AF, Walters JTR. 2020. Genome-wide association studies in schizophrenia: recent advances, challenges and future perspective. Schizophr Res. 217:4-12.

Depew MJ, Lufkin T, Rubenstein JL. 2002. Specification of jaw subdivisions by Dlx genes. Science 298(5592):381-385.

Dolgova O, Lao O. 2018. Evolutionary and medical consequences of archaic introgression into modern human genomes. Genes (Basel). 9:358.

Duveau J, Berillon G, Verna C, Laisne G, Cliquet D. 2019. The composition of a Neandertal social group revealed by the hominin footprints at Le Rozel (Normandy, France). Proc Natl Acad Sci U S A. 116(39):19409-19414.

Ey E, de Chaumont F, Bourgeron T. 2020. Spontaneous social communication in laboratory mice- placing ultrasonic vocalizations in their behavioral context. bioRxiv. 2020.07.09.195362.

Ey E, Torquet N, Le Sourd AM, Leblond CS, Boeckers TM, Faure $P$, Bourgeron T. 2013. The Autism ProSAP1/Shank2 mouse model displays quantitative and structural abnormalities in ultrasonic vocalisations. Behav Brain Res. 256:677-689.

Faedo A, Quinn JC, Stoney P, Long JE, Dye C, Zollo M, Rubenstein JL, Price DJ, Bulfone A. 2004. Identification and characterization of a novel transcript down-regulated in Dlx1/Dlx2 and up-regulated in Pax6 mutant telencephalon. Dev Dyn. 231(3):614-620.

Fazel Darbandi S, Poitras L, Monis S, Lindtner S, Yu M, Hatch G, Rubenstein JL, Ekker M. 2016. Functional consequences of I56ii Dlx enhancer deletion in the developing mouse forebrain. Dev Biol. 1606:30263-30269.

Feng J, Bi C, Clark BS, Mady R, Shah P, Kohtz JD. 2006. The Evf-2 noncoding RNA is transcribed from the Dlx-5/6 ultraconserved region and functions as a Dlx-2 transcriptional coactivator. Genes Dev. 20(11):1470-1484.

Gagliano Taliun SA, VandeHaar P, Boughton AP, Welch RP, Taliun D, Schmidt EM, Zhou W, Nielsen JB, Willer C), Lee S, et al. 2020. Exploring and visualizing large-scale genetic associations by using PheWeb. Nat Genet. 52(6):550-552.

Gandal MJ, Zhang P, Hadjimichael E, Walker RL, Chen C, Liu S, Won H, van Bakel $\mathrm{H}$, Varghese $M$, Wang $Y$, et al.; PsychENCODE Consortium. 2018. Transcriptome-wide isoform-level dysregulation in ASD, schizophrenia, and bipolar disorder. Science 362(6420):eaat8127.

Garagnani P, Marquis J, Delledonne M, Pirazzini C, Marasco E, Kwiatkowska KM, lannuzzi V, Bacalini MG, Valsesia A, Carayol J, et al. 2021. Whole-genome sequencing analysis of semi-supercentenarians. Elife 10:e57849.

Geiger M, Sánchez-Villagra MR, Lindholm AK. 2018. A longitudinal study of phenotypic changes in early domestication of house mice. $R$ Soc Open Sci. 5(3):172099.

Giuliani C, Garagnani P, Franceschi C. 2018. Genetics of human longevity within an eco-evolutionary nature-nurture framework. Circ Res. 123(7):745-772.

Giuliani C, Pirazzini C, Delledonne M, Xumerle L, Descombes P, Marquis J, Mengozzi G, Monti D, Bellizzi D, Passarino G, et al. 2017. Centenarians as extreme phenotypes: an ecological perspective to get insight into the relationship between the genetics of longevity and age-associated diseases. Mech Ageing Dev. 165(Pt B):195-201.

Guarasci F, D'Aquila P, Montesanto A, Corsonello A, Bellizzi D, Passarino G. 2019. Individual DNA methylation profile is correlated with age and can be targeted to modulate healthy aging and longevity. Curr Pharm Des. 25(39):4139-4149.

Hajdinjak M, Fu Q, Hubner A, Petr M, Mafessoni F, Grote S, Skoglund P, Narasimham V, Rougier H, Crevecoeur I, et al. 2018. Reconstructing the genetic history of late Neanderthals. Nature 555(7698):652-656.

Hamilton SP, Woo JM, Carlson EJ, Ghanem N, Ekker M, Rubenstein JL. 2005. Analysis of four DLX homeobox genes in autistic probands. BMC Genet. 6:52.

Hammerschmidt K, Reisinger E, Westekemper K, Ehrenreich L, Strenzke $\mathrm{N}$, Fischer J. 2012. Mice do not require auditory input for the normal development of their ultrasonic vocalizations. BMC Neurosci. 13:40.

Harris K, Nielsen R. 2016. The genetic cost of Neanderthal introgression. Genetics 203(2):881-891. 
Hinch AG, Tandon A, Patterson N, Song Y, Rohland N, Palmer CD, Chen GK, Wang K, Buxbaum SG, Akylbekova EL, et al. 2011. The landscape of recombination in African Americans. Nature 476:170-175.

Holy TE, Guo Z. 2005. Ultrasonic songs of male mice. PLoS Biol. 3(12):e386.

Huerta-Sanchez E, Jin X, Asan Bianba Z, Peter BM, Vinckenbosch N, Liang Y, Yi X, He M, Somel M, et al. 2014. Altitude adaptation in Tibetans caused by introgression of Denisovan-like DNA. Nature 512:194-197.

Huguet G, Benabou M, Bourgeron T. 2016. The genetics of autism spectrum disorders. In: Sassone-Corsi P, Christen Y, editors. A time for metabolism and hormones. Cham: Springer International Publishing. p. 101-129.

Jurgens U. 2009. The neural control of vocalization in mammals: a review. J Voice. 23:1-10.

Jurgens U. 2002. Neural pathways underlying vocal control. Neurosci Biobehav Rev. 26:235-258.

Juric I, Aeschbacher S, Coop G. 2016. The strength of selection against neanderthal introgression. PLoS Genet. 12(11):e1006340.

Konopka G, Roberts TF. 2016. Insights into the neural and genetic basis of vocal communication. Cell 164(6):1269-1276.

Lahvis GP, Alleva E, Scattoni ML. 2011. Translating mouse vocalizations: prosody and frequency modulation. Genes Brain Behav. 10(1):4-16.

Lindblad-Toh K, Garber M, Zuk O, Lin MF, Parker BJ, Washietl S, Kheradpour P, Ernst J, Jordan G, Mauceli E, et al.; Genome Institute at Washington University. 2011. A high-resolution map of human evolutionary constraint using 29 mammals. Nature 478(7370):476-482.

López-Tobón A, Trattaro S, Testa G. 2020. The sociability spectrum: evidence from reciprocal genetic copy number variations. Mol Autism. 11(1):50.

Maechler MR, Struyf A, Hubert M, Hornik K. 2019. cluster: cluster analysis basics and extensions. $R$ package version. 1(2):56.

Medvedeva VP, Rieger MA, Vieth B, Mombereau C, Ziegenhain C, Ghosh T, Cressant A, Enard W, Granon S, Dougherty JD, et al. 2019. Altered social behavior in mice carrying a cortical Foxp2 deletion. Hum Mol Genet. 28(5):701-717.

Merlo GR, Zerega B, Paleari L, Trombino S, Mantero S, Levi G. 2000. Multiple functions of Dlx genes. Int J Dev Biol. 44(6):619-626.

Meyer M, Kircher M, Gansauge MT, Li H, Racimo F, Mallick S, Schraiber JG, Jay F, Prüfer K, de Filippo C, et al. 2012. A high-coverage genome sequence from an archaic Denisovan individual. Science 338(6104):222-226.

Moles A, Costantini F, Garbugino L, Zanettini C, D'Amato FR. 2007. Ultrasonic vocalizations emitted during dyadic interactions in female mice: a possible index of sociability? Behav Brain Res. 182(2):223-230.

Myers TA, Chanock SJ, Machiela MJ. 2020. LDlinkR: an R package for rapidly calculating linkage disequilibrium statistics in diverse populations. Front Genet. 11:157.

Nakashima N, Yamagata T, Mori M, Kuwajima M, Suwa K, Momoi MY. 2010. Expression analysis and mutation detection of DLX5 and DLX6 in autism. Brain Dev. 32(2):98-104.

Nei M. 1973. Analysis of gene diversity in subdivided populations. Proc Natl Acad Sci U S A. 70(12):3321-3323.

O'Connell J, Gurdasani D, Delaneau O, Pirastu N, Ulivi S, Cocca M, Traglia M, Huang J, Huffman JE, Rudan I, et al. 2014. A general approach for haplotype phasing across the full spectrum of relatedness. PLoS Genet. 10(4):e1004234.

Paradis E, Schliep K. 2019. ape 5.0: an environment for modern phylogenetics and evolutionary analyses in R. Bioinformatics 35:526-528.

Perera M, Merlo GR, Verardo S, Paleari L, Corte G, Levi G. 2004. Defective neuronogenesis in the absence of Dlx5. Mol Cell Neurosci. 25(1):153-161.

Petr M, Pääbo S, Kelso J, Vernot B. 2019. Limits of long-term selection against Neandertal introgression. Proc Natl Acad Sci U S A. 116(5):1639-1644.

Peyregne S, Boyle MJ, Dannemann M, Prufer K. 2017. Detecting ancient positive selection in humans using extended lineage sorting. Genome Res. 27(9):1563-1572.
Poitras L, Yu M, Lesage-Pelletier C, Macdonald RB, Gagne JP, Hatch G, Kelly I, Hamilton SP, Rubenstein JL, Poirier GG, et al. 2010. An SNP in an ultraconserved regulatory element affects Dlx5/Dlx6 regulation in the forebrain. Development 137(18):3089-3097.

Prufer K, Racimo F, Patterson N, Jay F, Sankararaman S, Sawyer S, Heinze A, Renaud G, Sudmant PH, de Filippo C, et al. 2014. The complete genome sequence of a Neanderthal from the Altai Mountains. Nature 505(7481):43-49.

Purcell S, Neale B, Todd-Brown K, Thomas L, Ferreira MA, Bender D, Maller J, Sklar P, de Bakker PI, Daly MJ, et al. 2007. PLINK: a tool set for whole-genome association and population-based linkage analyses. Am J Hum Genet. 81(3):559-575.

Racimo F. 2016. Testing for ancient selection using cross-population allele frequency differentiation. Genetics 202(2):733-750.

Racimo F, Kuhlwilm M, Slatkin M. 2014. A test for ancient selective sweeps and an application to candidate sites in modern humans. Mol Biol Evol. 31(12):3344-3358.

Rasmussen MB, Kreiborg S, Jensen P, Bak M, Mang Y, Lodahl M, BudtzJørgensen E, Tommerup N, Tranebjærg L, Rendtorff ND. 2016. Phenotypic subregions within the split-hand/foot malformation 1 locus. Hum Genet. 135(3):345-357.

Yuen RKC, Merico D, Bookman M, L Howe J, Thiruvahindrapuram B, Patel RV, Whitney J, Deflaux N, Bingham J, Wang Z, et al. 2017. Whole genome sequencing resource identifies 18 new candidate genes for autism spectrum disorder. Nat Neurosci. 20(4):602-611.

Robledo RF, Rajan L, Li X, Lufkin T. 2002. The Dlx5 and Dlx6 homeobox genes are essential for craniofacial, axial, and appendicular skeletal development. Genes Dev. 16(9):1089-1101.

Rotival M, Quintana-Murci L. 2020. Functional consequences of archaic introgression and their impact on fitness. Genome Biol. 21(1):3.

Rousseeuw PJ. 1987. Silhouettes: a graphical aid to the interpretation and validation of cluster analysis. J Comput Appl Math. 20:53-65.

Sales GD. 1972. Ultrasound and aggressive behaviour in rats and other small mammals. Anim Behav. 20(1):88-100.

Sánchez-Villagra MR, van Schaik CP. 2019. Evaluating the selfdomestication hypothesis of human evolution. Evol Anthropol. 28(3):133-143.

Sangiamo DT, Warren MR, Neunuebel JP. 2020. Ultrasonic signals associated with different types of social behavior of mice. Nat Neurosci. 23(3):411-422.

Sankararaman S, Mallick S, Dannemann M, Prufer K, Kelso J, Paabo S, Patterson N, Reich D. 2014. The genomic landscape of Neanderthal ancestry in present-day humans. Nature 507(7492):354-357.

Sazzini M, Abondio P, Sarno S, Gnecchi-Ruscone GA, Ragno M, Giuliani C, De Fanti S, Ojeda-Granados C, Boattini A, Marquis J, et al. 2020. Genomic history of the Italian population recapitulates key evolutionary dynamics of both Continental and Southern Europeans. BMC Biol. 18(1):51.

Scherer SW, Poorkaj P, Massa H, Soder S, Allen T, Nunes M, Geshuri D, Wong E, Belloni E, Little S. 1994. Physical mapping of the split hand/ split foot locus on chromosome 7 and implication in syndromic ectrodactyly. Hum Mol Genet. 3(8):1345-1354.

Schmeisser MJ, Ey E, Wegener S, Bockmann J, Stempel AV, Kuebler A, Janssen AL, Udvardi PT, Shiban E, Spilker C, et al. 2012. Autistic-like behaviours and hyperactivity in mice lacking ProSAP1/Shank2. Nature 486(7402):256-260.

Shimizu M, Narboux-Nême N, Gitton Y, de Lombares C, Fontaine A, Alfama G, Kitazawa T, Kawamura Y, Heude E, Marshall L, et al. 2018. Probing the origin of matching functional jaws: roles of Dlx5/6 in cranial neural crest cells. Sci Rep. 8(1):14975.

Šimić G, Vukić V, Kopić J, Krsnik Ž, Hof PR. 2020. Molecules, mechanisms, and disorders of self-domestication: keys for understanding emotional and social communication from an evolutionary perspective. Biomolecules 11(1):2.

Simonti CN, Vernot B, Bastarache L, Bottinger E, Carrell DS, Chisholm RL, Crosslin DR, Hebbring SJ, Jarvik GP, Kullo IJ, et al. 2016. The phenotypic legacy of admixture between modern humans and Neandertals. Science 351(6274):737-741. 
Simonyan K. 2014. The laryngeal motor cortex: its organization and connectivity. Curr Opin Neurobiol. 28:15-21.

Skov L, Coll Macià M, Sveinbjörnsson G, Mafessoni F, Lucotte EA, Einarsdóttir MS, Jonsson $H$, Halldorsson B, Gudbjartsson DF, Helgason A, et al. 2020. The nature of Neanderthal introgression revealed by 27,566 Icelandic genomes. Nature 582(7810):78-83.

Snyder-Mackler N, Burger JR, Gaydosh L, Belsky DW, Noppert GA, Campos FA, Bartolomucci A, Yang YC, Aiello AE, O'Rand A, et al. 2020. Social determinants of health and survival in humans and other animals. Science 368(6493):eaax9553.

Tschida K, Michael V, Takatoh J, Han BX, Zhao S, Sakurai K, Mooney R, Wang F. 2019. A specialized neural circuit gates social vocalizations in the mouse. Neuron 103(3):459-472 e454.

Utsunomiya YT, Milanesi M, Utsunomiya AT, Ajmone-Marsan P, Garcia JF. 2016. GHap: an $\mathrm{R}$ package for genome-wide haplotyping. Bioinformatics 32(18):2861-2862.

Vacante $M$, D'Agata V, Motta $M$, Malaguarnera G, Biondi A, Basile F, Malaguarnera M, Gagliano C, Drago F, Salamone S. 2012. Centenarians and supercentenarians: a black swan. Emerging social, medical and surgical problems. BMC Surg 12 Suppl 1:S36.

Vernes SC, Nicod J, Elahi FM, Coventry JA, Kenny N, Coupe AM, Bird LE, Davies KE, Fisher SE. 2006. Functional genetic analysis of mutations implicated in a human speech and language disorder. Hum Mol Genet. 15(21):3154-3167.

Vernes SC, Oliver PL, Spiteri E, Lockstone HE, Puliyadi R, Taylor JM, Ho J, Mombereau C, Brewer A, Lowy E, et al. 2011. Foxp2 regulates gene networks implicated in neurite outgrowth in the developing brain. PLoS Genet. 7(7):e1002145.
Vernot B, Tucci S, Kelso J, Schraiber JG, Wolf AB, Gittelman RM, Dannemann M, Grote S, McCoy RC, Norton H, et al. 2016. Excavating Neandertal and Denisovan DNA from the genomes of Melanesian individuals. Science 352(6282):235-239.

Wang Y, Dye CA, Sohal V, Long JE, Estrada RC, Roztocil T, Lufkin T, Deisseroth K, Baraban SC, Rubenstein JL. 2010. Dlx5 and Dlx6 regulate the development of parvalbumin-expressing cortical interneurons. J Neurosci. 30(15):5334-5345.

Wilkins AS, Wrangham RW, Fitch WT. 2014. The "domestication syndrome" in mammals: a unified explanation based on neural crest cell behavior and genetics. Genetics 197(3):795-808.

Williams GC. 1957. Pleiotropy, natural selection, and the evolution of senescence. Evolution 11(4):398-411.

Wohr M. 2014. Ultrasonic vocalizations in Shank mouse models for autism spectrum disorders: detailed spectrographic analyses and developmental profiles. Neurosci Biobehav Rev. 43:199-212.

Yang YC, Boen C, Gerken K, Li T, Schorpp K, Harris KM. 2016. Social relationships and physiological determinants of longevity across the human life span. Proc Natl Acad Sci U S A. 113(3):578-583.

Zanella M, Vitriolo A, Andirko A, Martins PT, Sturm S, O'Rourke T, Laugsch M, Malerba N, Skaros A, Trattaro S, et al. 2019. Dosage analysis of the 7q11.23 Williams region identifies BAZ1B as a major human gene patterning the modern human face and underlying self-domestication. Sci Adv. 5(12):eaaw7908.

Zhou W, Nielsen JB, Fritsche LG, Dey R, Gabrielsen ME, Wolford BN, LeFaive J, VandeHaar P, Gagliano SA, Gifford A, et al. 2018. Efficiently controlling for case-control imbalance and sample relatedness in large-scale genetic association studies. Nat Genet. 50(9):1335-1341. 